\title{
Metabolic Pathways and Potencies of New Fentanyl Analogs
}

\author{
Maurice Wilde ${ }^{1,2}$, Simona Pichini ${ }^{3}$, Roberta Pacifici ${ }^{3}$, Adriano Tagliabracci ${ }^{4}$, \\ Francesco Paolo Busardò ${ }^{4 *}$, Volker Auwärter ${ }^{1}$ and Renata Solimini ${ }^{3}$
}

${ }^{1}$ Department of Forensic Toxicology, Institute of Forensic Medicine, Medical Center - University of Freiburg, Faculty of Medicine, University of Freiburg, Freiburg im Breisgau, Germany, ${ }^{2}$ Hermann Staudinger Graduate School, University of Freiburg, Freiburg im Breisgau, Germany, ${ }^{3}$ National Centre on Addiction and Doping, Istituto Superiore di Sanità, Rome, Italy, ${ }^{4}$ Unit of Forensic Toxicology, Section of Legal Medicine, Department of Excellence SBSP, Università Politecnica delle Marche, Ancona, Italy

OPEN ACCESS

Edited by:

Luis F. Callado,

University of the Basque Country,

Spain

Reviewed by:

Olof Beck,

Karolinska Institutet (KI), Sweden

Salahadin Abdi,

University of Texas MD Anderson

Cancer Center, United States

${ }^{*}$ Correspondence:

Francesco Paolo Busardò

fra.busardo@libero.it

Specialty section:

This article was submitted to

Neuropharmacology,

a section of the journal

Frontiers in Pharmacology

Received: 20 November 2018

Accepted: 26 February 2019

Published: 05 April 2019

Citation:

Wilde M, Pichini S, Pacifici R

Tagliabracci A, Busardò FP.

Auwärter V and Solimini R (2019)

Metabolic Pathways and Potencies

of New Fentanyl Analogs.

Front. Pharmacol. 10:238.

doi: 10.3389/fphar.2019.00238
Up to now, little is known about the metabolic pathways of new fentanyl analogs that have recently emerged on the drug markets worldwide with high potential for producing addiction and severe adverse effects including coma and death. For some of the compounds, limited information on the metabolism has been published, however, for others so far no information is available. Considering the well characterized metabolism of the pharmaceutically used opioid fentanyl and the so far available data, the metabolism of the new fentanyl analogs can be anticipated to generally involve reactions like hydrolysis, hydroxylation (and further oxidation steps), $\mathrm{N}$ - and $\mathrm{O}$-dealkylation and O-methylation. Furthermore, phase II metabolic reactions can be expected comprising glucuronide or sulfate conjugate formation. When analyzing blood and urine samples of acute intoxication cases or fatalities, the presence of metabolites can be crucial for confirmation of the uptake of such compounds and further interpretation. Here we present a review on the metabolic profiles of new fentanyl analogs responsible for a growing number of severe and fatal intoxications in the United States, Europe, Canada, Australia, and Japan in the last years, as assessed by a systematic search of the scientific literature and official reports.

Keywords: novel synthetic opioids, fentanyl analogs, fentanyl biotransformations, in vivo and in vitro metabolism, metabolic profile, receptor binding affinity, toxicity

\section{INTRODUCTION}

Opiates have been used for thousands of years to treat a broad variety of conditions. The first semisynthetic opioids (such as heroin) were derived from the opium alkaloid morphine. In association with the discovery and deeper investigation of the opioid receptors numerous synthetic, structurally diverse opioids were developed by research chemists and pharmaceutical companies. Fentanyl has first been synthesized by Paul Janssen in 1959 (Janssen, 1965) and was derived from the synthetic opioid meperidine. Its pharmacological action is 50-100 times more potent than morphine and 25-40 times more than heroin, and it is commonly used in anesthesia and pain treatment (US Drug Enforcement Administration [US DEA], 2015; National Institute on Drug Abuse [NIDA], 2016). Fentanyl and its clinically used analogs are regarded as highly potent $\mu$-opioid receptor agonists.

Besides the medicinal usage and progress in the therapeutic application of opioids, misuse of opioids has always been an issue. However, non-medical use of opioids often leads to health problems due to the high addictive potential of opioids and their severe acute side effects like 
respiratory depression. Repeated opiate and opioid use leads to tolerance, a contributing factor to opioid dependence. Development of tolerance is a controversially discussed topic and not fully understood yet. However, there is a consensus that different mechanism are involved, among them pharmacodynamic tolerance (adaptive changes in networks or pathways in organs and tissues affected by drug interaction), behavioral tolerance, pharmacokinetic (metabolic) tolerance and tachyphylaxis (Bespalov et al., 2016). In both clinical use and misuse tolerance may lead to dose escalation and finally severe adverse effects.

Over the last few years a wave of highly potent synthetic opioids emerged on the market of new psychoactive substances (NPS). These 'new synthetic opioids' (NSO) are often derived from fentanyl (also known as 'designer fentanyls', 'fentanyl derivatives', or 'fentalogs') and available at a cheaper cost compared to heroin (Marchei et al., 2018; Rothberg and Stith, 2018). Fentanyl analogs have recently been encountered as cutting agents in seized heroin samples, in ready-touse preparations like nasal sprays or as 'research chemicals' marketed via internet shops. These drugs have caused an increasing number of acute intoxications and fatalities in North America, as well as in Europe, Japan, Canada, and Australia (Pichini et al., 2017, 2018). Plenty of pharmacokinetic studies have been published evaluating and characterizing receptor binding and potency of fentanyl (Costa et al., 1992; France et al., 1995) and its clinically relevant analogs (Henriksen et al., 2005; Volpe et al., 2011). When comparing binding constants, it has to be kept in mind that variables like type of assay, choice of competitive ligand etc. significantly impact the experimental outcome and may lead to varying values for identical compounds. In contrast, information on pharmacological data - and in particular metabolism - of non-medically used fentanyl analogs is scant, with evident difficulties in identifying the molecules in biological fluids of the consumers in order to assess consumption (Armenian et al., 2018). In addition, ratios of parent compound and metabolite concentrations can help to examine the plausibility of specific scenarios in forensic toxicology (e.g., acute vs. slow accumulative poisoning). An early study assessing the opioid-like activity of several fentanyl metabolites in a guinea pig ileum assay found that norfentanyl, 4-ANPP (4-anilino- $N$-phenethylpiperidine) and 4anilinopiperidine (metabolites of fentanyl) were less potent than either fentanyl or morphine by several orders of magnitude (Schneider and Brune, 1986). The only metabolite showing significant activity in this study was a phenolic derivative hydroxylated at the 4-position of the phenylethyl moiety of fentanyl, the activity of which was found to lie between morphine and pethidine.

Nevertheless, some of the fentanyl analog metabolites might retain opioid activity with clinical relevance. What has been documented for fentanyl metabolism typically translates to the new designer fentanyls, which also show an extensive metabolism, however, to varying degrees. This review article summarizes the current knowledge on pharmacological data with a focus on the metabolism of novel fentanyl analogs.

\section{METHODS}

\section{Procedures for Assessment of Metabolic Profiles}

To investigate the metabolism of a distinct compound, in vivo or in vitro approaches can be used: in vivo studies are performed in animals or humans, whereas in vitro approaches include the use of human liver microsome preparations, human hepatocytes or fungi as models for metabolism. In general, in vivo studies in humans would be the best choice due to limited transferability of animal data, but require ethical approval and are often not feasible. Human self-administration studies or the investigation of body fluids of death cases can serve as an alternative if available. However, such studies may show biased metabolic profiles due to health conditions or enzymatic phenotypes of study subjects. In vitro approaches generally do not reflect the full human metabolism, but are much easier to implement. Human hepatocytes are a commonly used model simulating human hepatic metabolism. However, due to varying factors like cell line and culture environment, the metabolic profile resulting from hepatocyte incubation may vary and does often not reflect the metabolic profile obtained in vivo sufficiently. Human liver microsomes or fungi like Cunninghamella elegans are further tools to produce in vitro metabolites. They are relatively easy to handle and costefficient, but may lack the ability to produce the whole human metabolic spectrum.

Analytical identification of metabolites is usually performed by mass spectrometric techniques like liquid chromatographyhigh resolution mass spectrometry (LC-HRMS) and use of different scan modes of tandem mass spectrometry. Differentiation of isomers often affords isolation of specific metabolites and nuclear magnetic resonance (NMR) spectroscopy analysis.

\section{Literature Search}

MEDLINE for biomedical literature and EMBASE for pharmacological literature as well as multidisciplinary databases such as Scopus and Web of Science were searched using the following combined terms: fentanyl analogs or analogs or derivatives or designer fentanyls or fentalogs, fentanyl, remifentanil, sufentanil, alfentanil, acetylfentanyl, acryloylfentanyl (or acrylfentanyl), $\alpha$-methylfentanyl, butyr(yl)fentanyl, carfentanil, cyclopropylfentanyl, cyclobutylfentanyl, cyclopentylfentany, cyclohexylfentanyl, 2,2,3,3tetramethylcyclopropylfentanyl, crotonylfentanyl, 4-fluoroisobutyr(-yl)fentanyl, isofentanyl, furanylfentanyl, methoxyacetylfentanyl, ocfentanil, ortho-fluorofentanyl, tetrahydrofuranylfentanyl, metabolism, metabolic networks, metabolic pathways, $\mu$-opioid receptor, opioid receptor binding. Further studies were retrieved by hand search through the reference lists of the selected articles. Moreover, a search for reports was conducted on Institutional websites, to identify documentation published by international agencies or institutions including the United States Drug Enforcement Administration (US DEA), United States National Institute on Drug Abuse (NIDA), World 
Health Organization (WHO) and the European Monitoring Centre for Drugs and Drug Addiction (EMCDDA).

\section{GENERAL REMARKS}

\section{Opioid Receptors}

Opioid receptors are membrane bound G-protein coupled receptors predominantly located at the synaptic complex in the central nervous system but are also found in peripheral tissues. In the 1960s and 1970s first binding studies were performed by Van Praag and Simon (1966), Ingoglia and Dole (1970), Simon et al. (1973), Terenius (1973) and Pert and Snyder (1973) locating the opioid receptors in different brain areas using radiolabeled ligand assays. First proof for the existence of multiple opioid receptors was published by Martin (1967) proposing three different types of the opioid receptor $(\mu, \kappa$, and $\delta)$. The $\mu$-opioid receptor (MOR) named by its agonist morphine is mainly located in brain tissue and the gastrointestinal (GI) tract. This receptor mediates many of the typical opiate effects like analgesia, euphoria, miosis, physical dependence, reduced GI-mobility and respiratory depression. Three subtypes of the $\mu$-opioid receptor $\left(\mu_{1}, \mu_{2}\right.$, and $\left.\mu_{3}\right)$ have been identified, while $\mu_{1}$ is characterized best (Pan et al., 2005). The $\kappa$ - and $\delta$-opioid receptors are both found primarily in the brain tissue. For the $\kappa$-receptor three subtypes and for the $\delta$-receptors two subtypes have been identified (Rothman et al., 1989; Portoghese and Lunzer, 2003). In principal, the same central nervous effects are produced by activation of the $\kappa$ receptors as for the $\mu$ receptors, but additionally $\kappa$ receptor agonists can cause hallucination and dissociation. $\delta$-Opioid receptors are believed to contribute to analgesia as well, but also modulate immune response of myenteric neurons (Poonyachoti et al., 2001). Fentanyl and its analogs have been specifically designed for the activation of the $\mu$-opioid receptors and usually show high selectivity for this receptor type. This is one of the factors complicating a direct comparison of morphine and fentanyl potency. Considering potency regarding central nervous effects, transmission through the blood-brain barrier has to be taken into consideration, too.

\section{FENTANYL AND FENTANYL ANALOGS}

Fentanyl is a 2-phenylethyl-substituted 4-anilinopiperidine derivative carrying a propionylamide moiety linked to the aniline-nitrogen. In principle, there are four structural features which can potentially be modified, resulting in a huge variety of fentanyl analogs: (a) the piperidine ring, (b) the anilinophenyl ring, (c) the 2-phenylethyl substituent and (d) a carboxamide moiety linked to the anilino-nitrogen (Figure 1).

In the 1970s, Janssen Pharmaceutica patented a series of highly potent fentanyl derivatives, the $\mathrm{N}$-4-substituted 1-(2-arylethyl)4 -piperidinyl- $N$-phenylpropanamides, such as the medically used Sufentanil and Carfentanil (Janssen, 1979). Carfentanil, which has been approved for veterinary use (Wildnil $\left.{ }^{\circledast}\right)$ due to its extremely high potency, recently emerged as a designer drug on the recreational drug market, posing a huge health risk not only for users but also for first responders and law enforcement staff. Since the 1970s, a multitude of further analogs has been investigated (Brine et al., 1995; Wang et al., 1995; Vuckovic et al., 2009). One of the first fentanyl analogs on the designer drug market was the highly potent 3-methylfentanyl, methylated at the piperidine ring (a) (Figure 1) resulting in a pair of diastereomers (Van Bever et al., 1974). Several different substituents like halogen atoms, methyl or methoxy groups of the anilinophenyl ring (b) (Figure 1) have been published and some of these emerged on the designer drug market in recent years (United Nations Office on Drugs and Crime [UNODC], 2017). The 2-phenylethyl moiety (c) (Figure 1) substituted at the tertiary piperidinyl-nitrogen seems to improve receptor binding over non-substituted or methyl substituted compounds, presumably by fitting better into a hydrophobic cavity of the $\mu$-opioid-receptor in close proximity to the active binding site (Jiang et al., 2000; Subramanian et al., 2000). Fentanyl analogs modified at this moiety like $\alpha$-methylfentanyl have been reported to be involved in some fatal intoxication cases in the 1980s (Gillespie et al., 1982). The $\beta$-hydroxylated analog of 3-methylfentanyl, ohmefentanyl, has been well researched in the 1980s, showing extremely high potencies for some of the diastereomers (Subramanian et al., 2000). Modification of the propanamide moiety (d) (Figure 1) of fentanyl led to a huge variety of newly emerged fentanyl analogs in recent years (such as butyrfentanyl, furanylfentanyl, benzodioxole fentanyl, cyclopropylfentanyl, methoxyacetylfentanyl and many more). These derivatives are presently in the focus of research, since there is none or very little data available so far.

\section{Fentanyl}

Fentanyl is a medically used 4-Anilinopiperidine derivative like alfentanil, sufentanil, and remifentanil. These drugs are used in surgery as adjuncts to anesthesia, for sedation and for the treatment of acute and chronic pain (Van Bever et al., 1976; Van Daele et al., 1976; Kukanich and Papich, 2009).

First metabolism studies on fentanyl were conducted by Van Wijngaarden and Soudijn (1968) monitoring the parent compound and metabolites of radio-labeled fentanyl in urine and feces of rats after intravenous administration. In the late 1980s, Banks and Ferguson (1988) described fentanyl metabolism, indicating that several factors have to be taken into consideration in order to determine drug metabolism: administration routes (intravenous, subcutaneous, transdermal, transmucosal, and spinal), tissue chosen for analysis, isolation procedure and inter- and intra-individual variation that can influence metabolite formation and distribution (Streisand et al., 1991; Solassol et al., 2005).

Fentanyl ( $N$-phenyl- $N$-[1-(2-phenethyl)-4-piperidinyl]propanamide) has several sites for metabolic transformation. It is a heterocyclic tertiary aliphatic amine containing two different phenyl rings and an aromatic amide function. Tertiary aliphatic amines are biotransformed through a reversible reaction into tertiary amine oxides. The tertiary amines also undergo $\mathrm{N}$-dealkylation through the carbinolamine. When this process happens on the phenylethyl side chain, in addition to the secondary amine a phenylacetaldehyde 


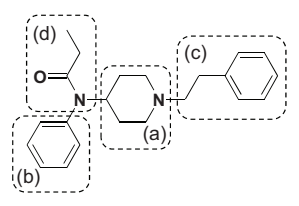

Fentanyl

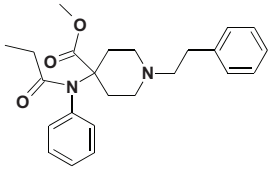

Carfentanil

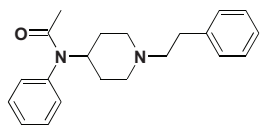

Acetylfentanyl

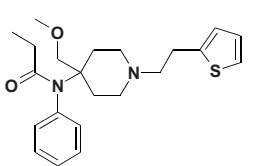

Sufentanil

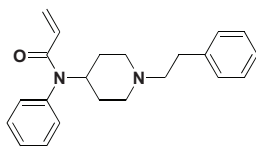

Acryloylfentanyl

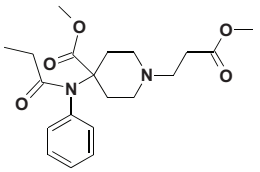

Remifentanil

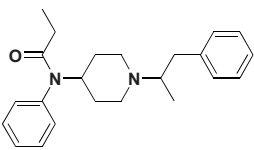

$\alpha$-Methylfentanyl

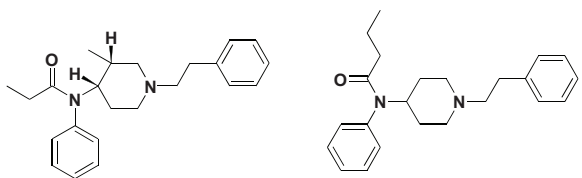

(+)-Cis-3-methylfentanyl Butyrfentanyl (3R,4S-configuration)*

(+)-Trans-3-methylfentanyl (3S,4S-configuration)*
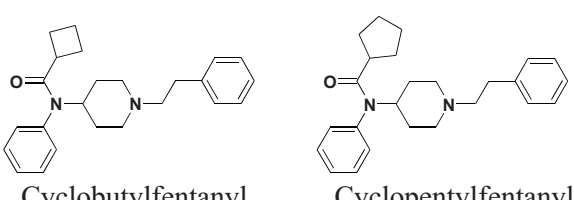

Cyclopentylfentanyl

Cyclopropylfentanyl

Cyclobutylfentanyl

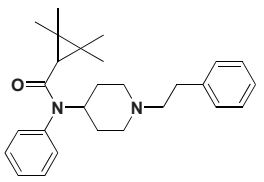

2,2,3,3-Tetramethylcyclopropylfentanyl

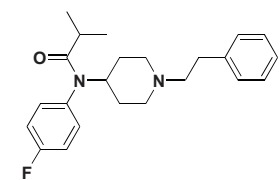

4-Fluoroisobutyrfentanyl

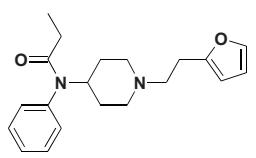

Furanylfentanyl

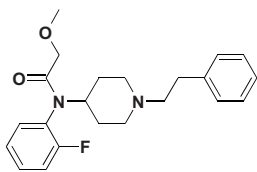

Ocfentanil

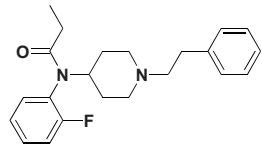

Ortho-fluorofentanyl

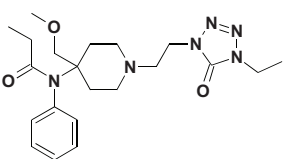

Alfentanil

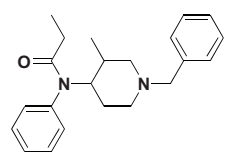

Isofentanyl

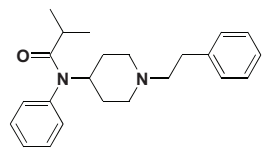

Isobutyrfentanyl

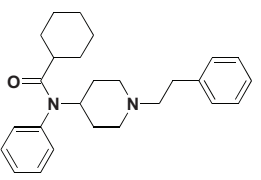

Cyclohexylfentanyl

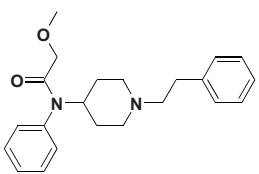

Methoxyacetylfentanyl

FIGURE 1 | Chemical structures of fentanyl and reviewed fentanyl analogs with data on metabolism and/or potency available in the scientific literature. The structures marked with '*' show only one of the two enantiomers.

is produced, which immediately oxidizes into phenylacetic acid. Oxidation at the 2-position of the piperidine ring generates a carbinolamine, which transforms into a more stable aminoaldehyde, resulting in ring cleavage. Aromatic rings undergo oxidation producing the equivalent phenolic derivatives. Furthermore, benzylic positions are more prone to oxidation. Amide functions usually undergo hydrolysis, and oxidation of the carbon chain is also frequent (Goromaru et al., 1984; Banks and Ferguson, 1988; Vardanyan and Hruby, 2014). 
In humans, fentanyl is mainly metabolized in the liver by CYP3A4 into norfentanyl through oxidative $N$-dealkylation at the piperidine ring by hepatic CYP3A4 and 3A5 isoenzymes, which is the principal pathway of metabolism (Feierman and Lasker, 1996; Guitton et al., 1997; Labroo et al., 1997; Gudin, 2012; Bista et al., 2014; Armenian et al., 2018). The inactive metabolites and less than $10 \%$ of the intact molecule are mainly excreted in urine and feces (Mercadante, 2015; Kuip et al., 2017; Armenian et al., 2018) and less than 1\% is metabolized by alkyl hydroxylation, combined $N$-dealkylation and hydroxylation or amide hydrolysis to the inactive compounds hydroxyfentanyl, hydroxy norfentanyl, and despropionylfentanyl (Kuip et al., 2017; $\mathrm{Wu}$ et al., 2017). The schematic human metabolic profile of fentanyl is depicted in Figure 2.

Fentanyl is also metabolized to norfentanyl in human duodenal microsomes; the mean rate is approximately half of the hepatic metabolism. Consequently, both intestinal and liver microsomes catalyze fentanyl metabolism and $N$-dealkylation

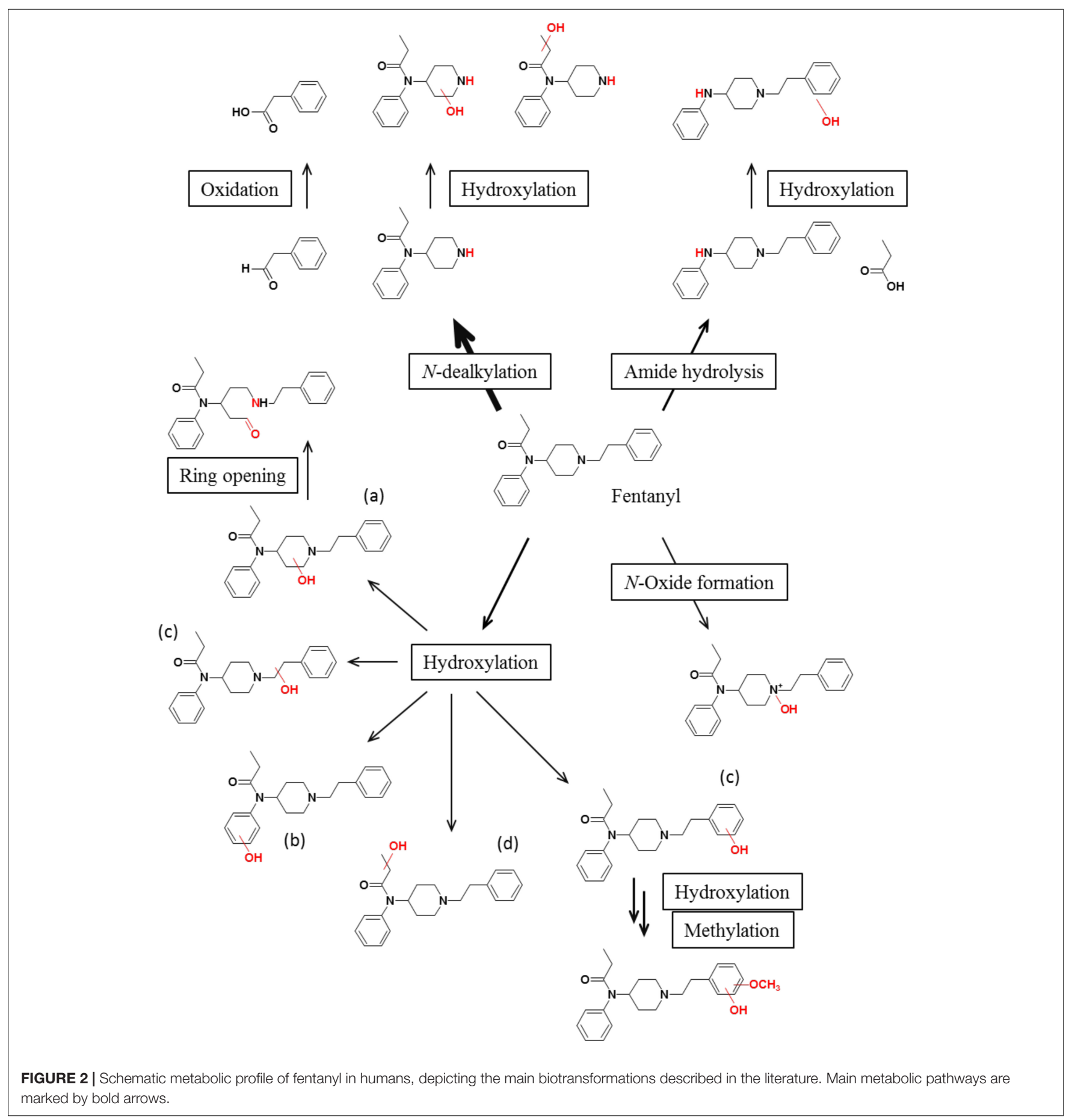


by CYP3A4 is the principal active enzyme in both organs (Labroo et al., 1997). Hydroxylation occurs on the 2 or 3 position of the piperidine ring (a) (Figure 1), at the phenyl ring of the anilino moiety (b) (Figure 1), at the ethyl linker or the phenyl ring of the phenethyl moiety (c) (Figure 1), or along the amide alkyl chain (d) (Figure 1). The 4'-hydroxyfentanyl and other hydroxylated metabolites might be bioactive (Schneider and Brune, 1986), although the majority is believed to be inactive. The metabolite $4^{\prime}$-hydroxyfentanyl can undergo biotransformation via a second hydroxylation to allow a catechol that is then $\mathrm{O}$-monomethylated to generate another metabolite. This reaction is probably catalyzed by the enzyme catechol-Omethyltransferase and presumably occurs at the $3^{\prime}$ position. This is technically a phase II metabolic product and can be detected in both hydrolyzed and non-hydrolyzed urine specimens due to its stability.

Minor metabolites such as hydroxypropionyl-fentanyl and hydroxypropionyl-norfentanyl are also created through different pathways without any relevant pharmacological activity. These metabolites have been detected in urine, stool and plasma (Bista et al., 2014).

Referring to despropionyl-fentanyl, another minor human metabolite, also known as 4-ANPP (Mahlke et al., 2014), results from carboxamide hydrolysis (Armenian et al., 2018).

Fentanyl is considered to be safer than morphine, in patients with liver and renal damage, because of a lack of metabolite accumulation (DePriest et al., 2015). Fentanyl activity can increase or decrease depending on genetic variations in the GI tract and in the liver, or through drugs which inhibit or induce CYP3A4. Fentanyl metabolism may be inhibited by macrolides, antifungal agents, and cimetidine (Bernard and Bruera, 2000). Serum fentanyl concentrations can vary significantly depending on liver function and the use of CYP3A4 inducers, therefore a model formula including these parameters has been provided, as a means to determine a transdermal fentanyl dose for the alleviation of cancer pain (Kokubun et al., 2012; Mercadante, 2015).

Bista and colleagues conducted a study to detect fentanyl and norfentanyl in plasma and saliva, showing that plasma and saliva had mean fentanyl concentrations of 0.785 and $3.335 \mu \mathrm{g} / \mathrm{L}$, respectively. Similarly, in plasma and saliva the mean norfentanyl concentration was 0.53 and $0.517 \mu \mathrm{g} / \mathrm{L}$, respectively. These data show that the concentration of fentanyl in saliva exceeds the concentration in plasma, suggesting an active transport into saliva. These data may in part be explained by the variable sample collection times with reference to time of dose, as distribution mechanisms will likely alter the saliva/plasma concentration ratio (Bista et al., 2014).

\section{Alfentanil, Sufentanil, Remifentanil}

In humans, the other fentanyl analogs frequently used in anesthesia - alfentanil, sufentanil, and remifentanil - are extensively metabolized and just a little percentage of the dose is excreted in urine without metabolic transformation. Metabolites such as norsufentanil and noralfentanil seem to be pharmacologically inactive (Valaer et al., 1997; Skulska et al., 2004).
Alfentanil (N-\{1-[2-(4-ethyl-5-oxo-4,5-dihydro-1Htetrazol-1-yl)ethyl]-4-(methoxymethyl)-piperidin-4-yl\}-Nphenylpropanamide) and sufentanil ( $N-\{4$-(methoxymethyl)-1[2-(thiophen-2-yl)ethyl]piperidin-4-yl\}- $N$-phenylpropanamide) are also principally metabolized in the liver via the CYP3A4 hepatic pathway, which generates the same $N$-dealkylated inactive metabolite, making a forensic distinction impossible when only this metabolite is detected (Armenian et al., 2018).

Compared to fentanyl, alfentanil has a smaller volume of distribution, greater binding to plasma proteins, less binding to red blood cells, a shorter elimination half-life, a slower total body clearance, and is less lipid soluble - characteristics which suggest that alfentanil would be an appropriate drug to give by continuous i.v. infusion (Fragen et al., 1983).

Sufentanil is metabolized by the liver and enterocytes of the small intestines, catalyzed by the cytochrome P450 enzyme system (Donk et al., 2018). Sufentanil metabolites are excreted in the urine. $N$-Dealkylation of sufentanil leads to mostly inactive metabolites such as the metabolites formed by oxidative $\mathrm{N}$-dealkylation at the piperidine ring (norsufentanil) or the phenylpropanamide nitrogen (leading to $N$-phenylpropanamide) and by aromatic hydroxylation (Lavrijsen et al., 1990; Tateishi et al., 1996; Koyyalagunta, 2007). Norsufentanil retains some activity, whereas the oxidative $O$-demethylation product (demethylsufentanil) is active retaining about $10 \%$ of the activity of sufentanil. However, it is produced in small quantities only and therefore not clinically relevant. The extensive metabolism of sufentanil in the GI tract is responsible for the low bioavailability following oral administration, so if a patient accidentally swallows a sublingual tablet this will result in under-dosing. Although the absence of clinically relevant metabolites makes sufentanil an option in mild-to-moderate renal impairment, there is insufficient data in patients with severe renal impairment, and hence careful patient monitoring is advised (Donk et al., 2018).

Remifentanil \{methyl 1-(3-methoxy-3-oxopropyl)-4[phenyl(propanoyl) amino]piperidine-4-carboxylate metabolized directly in the plasma by non-specific esterases, a hugely active group of enzymes found in blood and tissues throughout the body, resulting in an ultra-short duration of action (Rosow, 1999; Panzer et al., 2009). It is the only fentanyl analog that is $95 \%$ metabolized in the blood and tissues by non-CYP enzymes, because of an easily accessible ester group allowing for rapid hydrolysis by circulating blood esterases (Armenian et al., 2018). Its primary metabolite is remifentanil acid (a carboxylic acid derivative, GR90291), which has negligible pharmacological activity. Therefore, although remifentanil acid is excreted by the kidneys, remifentanil's action is not prolonged to a significant extent by renal injury or prolonged infusion in patients in intensive care (Panzer et al., 2009; Cascone et al., 2018). Experimental in vivo evaluations of the metabolic kinetics are presently not available (Cascone et al., 2018).

\section{Acetylfentanyl}

Acetylfentanyl ( $N$-Phenyl- $N$-[1-(2-phenylethyl)-4-piperidinyl] acetamide) is the acetyl amide analog of fentanyl. Relative potencies of several fentanyl analogs compared to fentanyl were 
evaluated by Higashikawa and Suzuki (2008a) in an animal study using the Litchfield-Wilcoxon test after peroral administration of diluted solutions of the fentanyl analogs to mice. $\mathrm{ED}_{50}$ and $\mathrm{LD}_{50}$ values obtained for acetylfentanyl were 0.021 and $9.3 \mathrm{mg} / \mathrm{kg}$, respectively, suggesting about $30 \%$ of the analgesic potency of fentanyl.

In general, acetylfentanyl is metabolized in a similar way to fentanyl. Acetylfentanyl has a major primarily inactive metabolite, acetyl norfentanyl, produced by $N$-dealkylation via CYP450 enzymes (Patton et al., 2014; Watanabe et al., 2017). Melent'ev et al. (2015) investigated metabolism of acetylfentanyl in urine samples collected from fatal intoxication cases with this fentanyl analog. In this study, besides the proposed main metabolite acetyl norfentanyl and the deacetylated acetylfentanyl metabolite (4-ANPP), primarily hydroxylated acetylfentanyl metabolites and their phase II conjugates were detected. Hydroxylated metabolites of acetylfentanyl were also identified after incubation with hepatocytes (Kanamori et al., 2018b), including a $4^{\prime}$-hydroxy-3'-methoxy-metabolite which has also been found as a metabolite of fentanyl and was also detected by Melent'ev et al. (2015) in the death cases involving acetylfentanyl. In an additional work Kanamori et al. (2018a) determined the involvement of different CYP isoenzymes in the formation of the metabolites of acetylfentanyl described above. Moreover, Watanabe et al. (2017) identified 31 metabolites of acetylfentanyl in human hepatocytes and authentic human urine samples, including the $\beta$-hydroxy and $4^{\prime}$-hydroxy-3'-methoxy metabolite, and several other phase I and phase II metabolites formed via various pathways such as glucuronidation, sulfation, dihydroxylation, monohydroxylation, carbonylation, and dihydrodiol formation.

\section{Acryloylfentanyl}

The fentanyl analog acryloylfentanyl (acrylfentanyl, $\mathrm{N}$-Phenyl$N$-[1-(2-phenylethyl)-4-piperidinyl]-acrylamide) differs from fentanyl only in dehydration in the 2,3-position of the propionylamide moiety. The competitive binding affinity of acryloylfentanyl was determined by Maryanoff et al. (1982) in rat brain using tritium-labeled naloxone. The $\mathrm{IC}_{50}$ value obtained was $1.4 \mathrm{nM}$ and therefore similar to fentanyl (IC $\mathrm{I}_{50}$ $1.6 \mathrm{nM})$. The analgesic properties of acryloylfentanyl were investigated by Essawi (1999) and it was found to be less potent than fentanyl (approximately $75 \%$ of fentanyl potency), but the analgesic effects persisted considerably longer. Though, the acrylamide moiety may lead to irreversible receptor binding and higher toxicity. However, $\mathrm{LD}_{50}$ values for acryloylfentanyl and fentanyl were 0.082 and $0.062 \mathrm{mg} / \mathrm{kg}$, respectively, suggesting similar acute toxicity.

Similarly to fentanyl, acryloylfentanyl is lipophilic and expected to easily cross the blood-brain barrier. Distribution into fat and other tissues seems likely due to the presumably high volume of distribution (Ujváry et al., 2017). The metabolic pathway of acryloylfentanyl shows similarity with the pathways of fentanyl and acetylfentanyl. The main metabolites generated by human hepatocytes in vitro and of those detected in the urine in a few fatalities, caused by acryloylfentanyl, and their chemical structures were recently described by Watanabe et al.
(2017). Overall, 14 biotransformation products, including major metabolites of acryloylfentanyl detected in human urine after hydrolysis of glucuronidated and/or sulfated phase II conjugates were identified in this work. The biotransformations involve an oxidative $\mathrm{N}$-dealkylation, presumably catalyzed by cytochrome P450 (CYP450) enzymes, leading to the desphenethyl metabolite acryloylnorfentanyl which is biologically inactive. Furthermore, monohydroxylations were observed either at the alkyl linker of the phenylethyl moiety or at the piperidine ring. Dihydroxylation of the phenyl ring of the phenylethyl moiety resulting in a catechol structure followed by $\mathrm{O}$-monomethylation were additional oxidative metabolic processes leading to similar metabolites as described for acetylfentanyl in the same work. Similar to fentanyl metabolism, amide hydrolysis (deacylation) results in a minor metabolite 4-ANPP, which is a common metabolite of fentanyl, acryloylfentanyl and several other fentanyl analogs. Acryloylfentanyl was also present in the urine of the deceased individuals.

With respect to acryloylfentanyl, the major human urinary metabolites identified in vivo (fatal cases) were acryloylnorfentanyl, as well as mono- and dihydroxylated derivatives and their conjugates (Watanabe et al., 2017).

\section{$\alpha$-Methylfentanyl and (cis/trans)-3-Methylfentanyl}

As one of the mono-methylated fentanyl derivatives, $\alpha$-methylfentanyl (N-Phenyl- $N$-[1-(1-phenyl-2-propanyl)4-piperidinyl]propanamide) carries the additional methyl group at the 1-position of the ethyl bridge of the phenethyl moiety. The diastereomeric pairs of enantiomers cis-3-methylfentanyl and trans-3-methylfentanyl carry the additional methyl group at the 3 -position of the piperidine ring. The analgesic activity of these derivatives proved to be similar to fentanyl or higher. In a study of Higashikawa and Suzuki (2008a) $\alpha$-methylfentanyl showed a very similar $\mathrm{ED}_{50}$ value as fentanyl $(0.0058$ and $0.0061 \mathrm{mg} / \mathrm{kg}$, respectively). However, toxic effects occurred at significantly lower doses of $\alpha$-methylfentanyl when compared to fentanyl $\left(\mathrm{LD}_{50}\right.$ values 8.6 and $62 \mathrm{mg} / \mathrm{kg}$, respectively). Van Bever et al. (1974) synthesized the different isomers of $\alpha$-methylfentanyl and 3-methylfentanyl and investigated their relative analgesic potencies. $\mathrm{ED}_{50}$ values for $\alpha$-methylfentanyl $(0.0085 \mathrm{mg} / \mathrm{kg})$ obtained in this work were in agreement with the reported values of Higashikawa and Suzuki (2008a), although fentanyl showed a higher value here $(0.011 \mathrm{mg} / \mathrm{kg})$. The $( \pm)$-trans-3methylfentanyl enantiomers $\left(\mathrm{ED}_{50} 0.0094 \mathrm{mg} / \mathrm{kg}\right.$ ) showed about the same effective dose as $\alpha$-methylfentanyl, but the $( \pm)$-cisenantiomers turned out to be even more potent and exhibited a significant difference between the $(+)$ - and $(-)$-enantiomer. The most potent isomer was $(+)$-cis-3-methylfentanyl $\left(\mathrm{ED}_{50}\right.$ $0.00058 \mathrm{mg} / \mathrm{kg}$ ) being about 20 times more potent than fentanyl, whereas the (-)-cis-isomer showed only $20 \%$ of the potency of fentanyl.

The first reports about detection of a metabolite of $\alpha$-methylfentanyl were published by Gillespie (Gillespie et al., 1982), who found the hydrolysis product despropionyl$\alpha$-methylfentanyl in several biological samples of fatal 
intoxication cases. Higashikawa and Suzuki (2008b) investigated the metabolism of $\alpha$-methylfentanyl in urine after administration to rats. The main metabolite formed by $N$-dealkylation in this study was norfentanyl, a metabolite shared with fentanyl. Furthermore, two metabolites in common with fentanyl were formed by further hydroxylation of the propionylamide moiety of norfentanyl [ $\omega$-hydroxypropionylnorfentanyl and ( $\omega$-1)-hydroxypropionyl-norfentanyl]. However, four additional metabolites were identified enabling differentiation of $\alpha$-methylfentanyl and fentanyl consumption resulting from mono- and dihydroxylation of $\alpha$-methylfentanyl [ $\omega$-hydroxypropionyl- $\alpha$-methylfentanyl, ( $\omega$-1)-hydroxypropionyl- $\alpha$-methylfentanyl, $\quad$ para-hydroxyphenyl- $\alpha$-methylfentanyl and para-hydroxyphenyl$\omega$-hydroxypropionyl- $\alpha$-methylfentanyl].

Investigations in rat performed by Sato et al. (2010) confirmed the findings of Higasikawa and Suzuki regarding the metabolic spectrum and demonstrated the time-course of metabolite excretion as well as the proportions of metabolites excreted in rat urine over a $96 \mathrm{~h}$ time period. Non-specific metabolites of $\alpha$-methylfentanyl were detectable up to $72 \mathrm{~h}$ after administration, whereas the specific metabolites were completely eliminated after $48 \mathrm{~h}$ and accounted for only $2-3 \%$ of the total amount of metabolites excreted in urine.

First detection of single metabolites of the methylated fentanyl analog 3-methylfentanyl was reported by Hammargren and Henderson (1988) who detected the dealkylated metabolite nor3-methylfentanyl in urine of suspected drug users. A systematic investigation of the metabolism of 3-methylfentanyl was done by Meyer et al. (2012) proposing a metabolic pathway for this fentanyl analog and reporting 9 phase I and 5 corresponding phase II metabolites in rat urine after drug administration. In accordance to Hammargren and Henderson, the main metabolite detected was nor-3-methylfentanyl formed by oxidative $N$-dealkylation. Further oxidation of this metabolite led to formation of hydroxypropionyl-nor-3-methylfentanyl and hydroxyphenyl-nor-3-methylfentanyl. In addition, mono- and dihydroxylations were observed primarily at the phenylethyl and the propionylamide moiety followed by either further oxidative reactions leading to a carboxy-propionyl metabolite or methylation of the 3,4-dihydroxyphenyl metabolite leading to a 3-methoxy-4-hydroxy metabolite in analogy to previously reported fentanyl and fentanyl analog metabolites. Furthermore, Meyer et al. (2012) also reported phase II glucuronic acid conjugates detected for hydroxylated metabolites.

\section{Isofentanyl}

Isofentanyl ( $N$-(1-benzyl-3-methylpiperidin-4-yl)- $N$-phenylpropanamide) was clandestinely synthesized to circumvent 3methylfentanyl regulation.

Meyer and collaborators identified isofentanyl together with 3-methylfentanyl phase I and phase II metabolites in rat urine (Meyer et al., 2012). Isofentanyl is an isomer of fentanyl and shares some main fragment ions in MS analysis. Metabolites such as the nor-metabolite can help to unequivocally prove uptake of this compound. For isofentanyl 11 phase I and 4 phase II metabolites were identified. The following metabolic steps could be postulated: $N$-dealkylation resulting in a common metabolite with 3-methylfentanyl (nor-3-methylfentanyl = norisofentanyl) followed by hydroxylations of the alkyl and/or aryl moiety, hydroxylation of the propionylamide side chain followed by oxidation to the corresponding carboxylic acid, and hydroxylations of the benzyl moiety followed by methylation resulting in the corresponding 3-methoxy-4-hydroxy metabolite. In addition, $N$-oxidation of isofentanyl was also observed. Some hydroxylated metabolites were partly excreted as glucuronides. Using recombinant human isoenzymes, CYP2C19, CYP2D6, CYP3A4, and CYP3A5 were found to be involved in the initial metabolic steps. The parent drugs could not be detected in urine. Their common nor-metabolite was suggested as a common target for urine screening for 3-methylfentanyl and isofentanyl. Targeting less abundant specific metabolites may enable differentiation of an uptake of either of the drugs (Meyer et al., 2012).

\section{Butyrfentanyl and Isobutyrfentanyl}

Butyrfentanyl (N-Phenyl- $N$-[1-(2-phenylethyl)-4-piperidinyl] butanamide) belongs to the mono-methylated fentanyl derivatives carrying the additional methyl group at the $\omega$-carbon of the propionyl amide resulting in a butyryl amide analog of fentanyl. Isobutyrfentanyl is the isomer carrying the additional methyl group at the $\alpha$-carbon of the propionylamide moiety. Both compounds were included in the activity studies of Higashikawa and Suzuki (2008a). In a study from Alburges et al. (1992) the binding affinity of butyrfentanyl to the $\mu$-opioid receptor was reported $\left(K_{\mathrm{i}}=32 \pm 4.1 \mathrm{nM}\right)$, which is about 32 -fold lower than the binding affinity of fentanyl $\left(K_{\mathrm{i}}=1.03 \pm 0.15 \mathrm{nM}\right)$.

Metabolites of butyrfentanyl were detected and identified in a fatal poisoning described by Staeheli et al. (2016) with focus on the post mortem tissue distribution and redistribution, a phenomenon often observed when analyzing post mortem samples. The identified metabolites were norbutyrfentanyl, carboxybutyrfentanyl, hydroxybutyrfentanyl, and desbutyrfentanyl. In pursuit of elucidation of the metabolism of butyrfentanyl, blood and urine samples of the same fatal intoxication case in conjunction with in vitro studies producing phase I and phase II metabolites of butyrfentanyl were investigated by Steuer et al. (2017). Human liver microsomes and recombinant cytochrome P450 enzymes (CYP) were used for in vitro assays. Butyrfentanyl was shown to undergo extensive metabolism. In total, 36 metabolites were identified in this study. The postulated primary metabolic pathways were hydroxylations at the butanamide side chain (in two positions), the phenylethyl moiety and the piperidine ring, oxidative $\mathrm{N}$-dealkylation, formation of $\mathrm{N}$-oxides and hydrolysis of the acyl moiety. Besides that, combinations of these biotransformations and additional reactions were observed leading to, e.g., carboxylated metabolites by further oxidation of the $\omega$-hydroxy-butanamide moiety or methylation of the 3,4-catechol moiety of dihydroxylated metabolites forming the respective 3-methoxy-4-hydroxy metabolites. Furthermore phase II conjugates were detected in the human post mortem samples for nine metabolites (eight glucuronic acid conjugates and one sulfate). The main metabolites detected in the in vitro studies, nor-butyrfentanyl, 
butyrohydroxy-butyrfentanyl and phenylethyl-hydroxybutyrfentanyl, were not in agreement with the main metabolites detected in authentic biological samples. The main metabolites detected in vivo were carboxy-butyrfentanyl in blood and carboxy-butyrfentanyl, butyrohydroxy-butyrfentanyl and carboxy-phenylethyl-hydroxy-butyrfentanyl in urine. Initial screening experiments with the most relevant CYPs indicated that mainly CYP2D6 and 3A4 were involved in the primary metabolic steps. Therefore, variability of phenotypes regarding these enzymes may have an influence on the metabolic profile in vivo. As a strategy to reach maximum detectability it seems advisable to include metabolites formed by different pathways as targets into analytical methods.

\section{Carfentanil}

Carfentanil [methyl 1-(2-phenylethyl)-4-[phenyl(propanoyl) amino]piperidine-4-carboxylate] is a member of the N-4 substituted fentanyl analogs carrying an additional methylcarboxylate moiety at the 4-position of the piperidine ring. This group of fentanyl analogs turned out to be significantly more potent than their non-substituted analogs. Carfentanil is about 10,000 times more potent than morphine and shows 30-100 times the potency of fentanyl (Van Bever et al., 1976), thereby representing the most potent approved opioid drug. Receptor binding affinity and analgesic activity of this compound has been investigated extensively by many research groups, reporting $\mathrm{ED}_{50}$ values from $0.00032 \mathrm{nM}$ up to $0.0017(<0.01) \mathrm{nM}$ and $K_{\mathrm{i}}$ values for the $\mu$-opioid receptor of $0.024 \mathrm{nM}$ up to $0.15 \mathrm{nM}$ (Thompson et al., 1987; Costa et al., 1992; Maguire et al., 1992; Villemagne et al., 1994; Bi-Yi et al., 1999; Jewett and Kilbourn, 2004; Henriksen et al., 2005). Carfentanil is used in veterinary medicine as general anesthetic, for pain management, and to immobilize large animals (Kukanich and Papich, 2009).

Due to its extremely high potency studies assessing the metabolism of carfentanil in humans have not been performed yet and it seems unlikely that they would be approved by an Ethics Committee. Though, metabolites of carfentanil have only been detected in fatal intoxication cases so far, the most well-known case being the Moscow Theater hostagetaking (Riches et al., 2012). Riches et al. (2012) detected the $N$-dealkylated metabolite norcarfentanil in a donated urine sample. Norcarfentanil is a common (minor) metabolite of the fentanyl analog remifentanil. First and only studies assessing the metabolic pathways of carfentanil were performed by Feasel et al. (2016) using metabolism predictions software (Molecular Discovery's MetaSite software and Simulations Plus's ADMET Predictor) for first in silico prediction and human liver microsomes and hepatocytes as in vitro models.

In total, 12 metabolites were identified for carfentanil, 11 phase I metabolites and 1 phase II conjugate as glucuronide. The following metabolic reactions or combinations of these were observed: oxidative $N$-dealkylation, ester hydrolysis, hydroxylation and $N$-oxide formation. The most abundant metabolites reported were formed by $N$-dealkylation partly followed by ester hydrolysis or hydroxylation. Hydroxylations occurred at the propionylamide side chain, at the phenylethyl moiety or at the piperidine ring resulting in formation of eight hydroxylated metabolites, and five of them showed an additional biotransformation (ester hydrolysis, $\mathrm{N}$-oxide formation or glucuronidation) or were further oxidized to ketones. Three $N$-oxide metabolites were reported with minor abundances, formed by oxidation of either the piperidine nitrogen or the anilino-nitrogen linked in the amide moiety. In contrast to studies concerning the metabolism of other fentanyl analogs so far, no amide hydrolysis metabolites or hydroxy-methoxy metabolites have been reported in this study.

\section{Alicyclic Fentanyl Analogs: Cyclopropylfentanyl, Cyclobutylfentanyl Cyclopentylfentanyl, Cyclohexylfentanyl and 2,2,3,3-Tetramethylcyclopropyl- Fentanyl}

This subgroup of newly emerging fentanyl analogs structurally differs in the aliphatic amide linked moiety, which is substituted by an aliphatic cyclic moiety in these compounds. Concerning the receptor binding affinities and potencies only cyclopropylfentanyl has been evaluated so far. In vitro studies using chinese hamster ovary $(\mathrm{CHO})$ and rat cell preparations expressing the three types of opioid receptors were used for determination of binding affinities. Cyclopropylfentanyl binds selectively to the $\mu$-opioid receptor (vs. $\left[{ }^{3} \mathrm{H}\right]$-DAMGO) with $K_{\mathrm{i}}$ values of $0.088 \pm 0.027 \mathrm{nM}$ for the $\mu$-opioid receptor as well as $59.4 \pm 3.0 \mathrm{nM}$ and $36 \pm 10 \mathrm{nM}$ for the $\delta$ - and $\kappa$-opioid receptors, respectively. $\mathrm{EC}_{50}$ values were determined employing a $\left[{ }^{35} \mathrm{~S}\right] \mathrm{GTP} \gamma \mathrm{S}$ binding assay, resulting in $10.8 \pm 2.7 \mathrm{nM}$ for cyclopropylfentanyl at the $\mu$-opioid receptor compared to $32 \pm 11 \mathrm{nM}$ for fentanyl, showing a more or less similar (about threefold higher) potency to fentanyl (Drug Enforcement Administration-Veterans Affairs (DEA-VA) Interagency Agreement, 2017; European Monitoring Centre for Drugs Drug Addiction [EMCDDA], 2018b). For the other alicyclic analogs no literature on receptor binding affinities and potencies is available yet. Theoretically, these analogs may imitate the steric requirements for receptor binding of fentanyl. They probably show similar or lower potency than fentanyl, in analogy to butyrand valerylfentanyl which have been reported to be less potent.

A study investigating metabolism of this group of compounds has been published very recently by Åstrand et al. (2018) using human hepatocytes. Seven metabolites were identified for cyclopropylfentanyl, and the most abundant metabolite was norcyclopropylfentanyl formed by oxidative $N$-dealkylation. Other metabolic reactions observed were monohydroxylation, dihydroxylation followed by subsequent methylation, dihydrodiol and $\mathrm{N}$-oxide formation. The glucuronic acid conjugate of the most intense hydroxy metabolite (hydroxylated at the piperidine ring) was detected as well. Hydroxylation of the cyclopropyl moiety or amide hydrolysis has not been detected in this study. The main metabolite norcyclopropylfentanyl has also been detected by Maher et al. (2018) in urine samples of two death cases and Palaty et al. (2018) in several urine samples of patients with a substance use disorder from two canadian provinces. 
The major metabolites detected for cyclobutylfentanyl by Åstrand et al. (2018) were also $N$-dealkylation and, in contrast to cyclopropylfentanyl, hydroxylation of the cyclobutyl moiety and amide hydrolysis leading to a metabolite found in common with fentanyl, 4-ANPP. Further mono- and dihydroxylated metabolites were identified, mainly hydroxylated at the cyclobutyl moiety, the piperidine ring or the phenylethyl moiety.

In agreement with findings of cyclobutylfentanyl, the most abundant metabolites found were hydroxylations of the cyclopentyl moiety and nor-cyclopentylfentanyl. Moreover, another monohydroxlated metabolite (at the piperidine ring) and two monohydroxylated normetabolites (both at the cyclopentyl ring), a dihydroxylated metabolite (at the piperidine ring and the cyclopentyl ring), the amide hydrolysis product 4-ANPP and two further oxidation products ( $\mathrm{N}$ oxide and carbonyl metabolite) were formed to a minor extent in this assay.

Incubation of cyclohexylfentanyl with hepatocytes mainly led to the amide hydrolysis product 4-ANPP, norcyclohexylfentanyl and two monohydroxlated metabolites (both modified at the cyclohexyl moiety). Again, further hydroxylated metabolites were detected, comprising monohydroxlation, dihydroxylation, and hydroxylations in a second metabolic step primarily at the cyclohexyl and the piperidine ring.

Substitution of the amide linked alkyl chain with a 2,2,3,3-tetramethylcyclopropyl moiety seemed to steer metabolic reactions to this part of the molecule. Except for the nor2,2,3,3-tetramathylcyclopropylfentanyl metabolite, which was formed to a minor extent, all metabolites showed at least one biotransformation of the 2,2,3,3-tetramethylcyclopropyl moiety. Monohydroxylations and dihydroxylations and subsequent further oxidation steps resulting in the formation of, e.g., carboxylic acids have been reported by Åstrand et al. (2018).

\section{4-Fluoroisobutyrfentanyl (4F-iBF, Para-Fluoroisobutyrfentanyl)}

4-fluoroisobutyrfentanyl (4-fluoro-isobutylfentanyl ( $N$-(4fluorophenyl)-2-methyl- $N$-[1-(2-phenylethyl)-4-piperidinyl] -propanamide) is one of the fluorinated fentanyl analogs that emerged on the NPS drug market recently. For this analog no data on binding affinity and selectivity to the $\mu$-opioid receptor is available. The potency of $4 \mathrm{~F}-\mathrm{iBF}$ might be similar or lower than the potency of butyrfentanyl/isobutyrfentanyl, following the evaluation of fluorinated derivatives by Higashikawa and Suzuki (2008a). Metabolism of 4F-iBF was investigated by Watanabe et al. (2017) using hepatocyte incubates and analyzing authentic urine samples. In total, 17 metabolites were found and the following biotransformations were observed: $\mathrm{N}$-dealkylation, monohydroxylations, dihydroxylations and subsequent methylation and glucuronidation, dihydrodiol formation, amide hydrolysis, carbonylation and carboxylation. Nine metabolites were identified in the hepatocyte assay. The most abundant ones were nor- $4 \mathrm{~F}-\mathrm{iBF}$, and two hydroxylated metabolites (at the piperidine ring or the phenylethyl moiety). Analysis of the urine samples after conjugate cleavage revealed 11 metabolites, resulting in a similar metabolic profile as obtained from the hepatocyte incubation assay, although the hydroxymethoxy metabolite was more dominant in the authentic urine sample. Two additional glucuronic acid conjugates were detected when analyzing the urine without hydrolysis prior to extraction.

\section{Furanylfentanyl}

Binding affinity studies on furanylfentanyl have been performed in vitro using $\mathrm{CHO}$ and rat cell preparations expressing the three types of opioid receptors. Furanylfentanyl binds selectively to the $\mu$-opioid receptor (vs. $\left[{ }^{3} \mathrm{H}\right]$-DAMGO) with $K_{\mathrm{i}}$ values of $0.028 \pm 0.008 \mathrm{nM}$ for the $\mu$-opioid receptor as well as $54 \pm 15 \mathrm{nM}$ and $59.2 \pm 6.4 \mathrm{nM}$ for the $\delta$ - and $\kappa$-opioid receptors, respectively. In vitro $\mathrm{EC}_{50}$ values were determined employing a $\left[{ }^{35} \mathrm{~S}\right] \mathrm{GTP} \gamma \mathrm{S}$ binding assay, resulting in $2.52 \pm 0.46 \mathrm{nM}$ for furanylfentanyl compared to $17.9 \pm 4.3 \mathrm{nM}$ for fentanyl at the $\mu$-opioid receptor, suggesting a sevenfold higher potency for furanylfentanyl over fentanyl (Drug Enforcement Administration-Veterans Affairs (DEA-VA) Interagency Agreement, 2016; European Monitoring Centre for Drugs Drug Addiction [EMCDDA], 2017). In the patent literature of furanylfentanyl an in vivo $\mathrm{ED}_{50}$ value $(0.02 \mathrm{mg} / \mathrm{kg})$ was reported after i.v. administration to mice, but comparative data of fentanyl or morphine was not reported (Huang et al., 1986).

Goggin et al. (2017) identified four metabolites of furanylfentanyl after analyzing 500 urine samples of opioid intoxication cases. The most pronounced metabolites detected in 42 out of 51 cases positive for furanylfentanyl was the hydrolysis product 4-ANPP and its sulfate conjugate. Moreover, a very unique metabolite formed by dihydrodiol formation of the heterocyclic furanyl moiety was detected in $86 \%$ of the cases. The $\mathrm{N}$-dealkylated metabolite norfuranylfentanyl was detected in only four of the furanylfentanyl positive cases indicating that substitution of the amide linked moiety of the fentanyl analogs to a furanyl-carboxamide shifts the metabolic profile of this compound toward a hydrolytic reaction and biotransformation of the furanyl moiety. In accordance with these findings, Mohr et al. (2016) detected 4-ANPP in five out of eight fatal intoxications with furanylfentanyl and Martucci et al. (2018) reported detection and distribution of the hydrolysis metabolite 4-ANPP in various tissues of a fatal furanylfentanyl intoxication case. In total, 17 and 14 phases I and II metabolites of furanylfentanyl were identified in a more detailed in vitro approach by Richeval et al. (2017) and Watanabe et al. (2017) using human liver microsomes and hepatocytes. In contrast to the findings of Goggins and Martucci, the spectrum of metabolic reactions in these in vitro studies comprised several hydroxylations, $\mathrm{N}$-oxide formation and glucuronidation besides the already mentioned amide hydrolysis (plus sulfate conjugation), dihydrodiol formation and $\mathrm{N}$-dealkylation. The most abundant in vitro metabolites reported by both authors were the hydrolysis product 4-ANPP, a dihydrodiol metabolite and norfuranylfentanyl. Additionally, a metabolite formed by oxidative ring-opening of the furanyl ring (and further oxidation to a carboxylic acid) was reported by both groups. Since metabolism of furanylfentanyl has been studied by a couple of research groups it can be said, that $\mathrm{N}$-dealkylation which often leads to main metabolites of fentanyl and fentanyl 
analogs in vitro and in vivo, plays a minor role in the metabolism of furanylfentanyl, whereas amide hydrolysis and oxidative transformations of the furanyl moiety (such as dihydrodiol formation) are major biotransformation steps seen both in vitro and in vivo for this compound.

\section{Methoxyacetylfentanyl}

Methoxyacetylfentanyl is one of the numerous newly emerged fentanyl analogs differing from fentanyl by the modification of the $N$-acyl moiety. Structure activity relationships of methoxyacetylfentanyl and several other alkyloxy derivatives were investigated by Bagley et al. (1991) reporting an $\mathrm{ED}_{50}$ value of $0.053 \mathrm{mg} / \mathrm{kg}$ for methoxyacetylfentanyl. Compared to the $\mathrm{ED}_{50}$ of $0.018 \mathrm{mg} / \mathrm{kg}$ for fentanyl, about $30 \%$ of the potency of fentanyl can be assumed for this compound.

Metabolism of methoxyacetylfentanyl (2-methoxy- $N$ (1-phenethylpiperidin-4-yl)- $N$-phenylacetamide) was first examined in vitro using a human liver microsomal preparation (European Monitoring Centre for Drugs Drug Addiction [EMCDDA], 2018a). A main metabolic step for methoxyacetylfentanyl appears to be $O$-demethylation leading to 2-hydroxyacetamide metabolite. Further metabolic reactions were $N$-dealkylation, hydroxylations of the piperidine ring and the phenylethyl side chain, $\mathrm{N}$-oxidation, as well as amide hydrolysis to 4-ANPP.

Mardal et al. (2018) investigated the in vitro and in vivo metabolic profiles of methoxyacetylfentanyl in the context of three case reports on deaths related to methoxyacetylfentanyl and by applying an additional in vitro study using human hepatocytes. A total of 10 methoxyacetylfentanyl metabolites were identified in hepatocyte incubates and biological samples. The metabolic pathways comprised mono- and dihydroxylations (at the phenylethyl ring or the anilinophenyl ring), $\mathrm{N}$-dealkylation, $\mathrm{O}$-demethylation, amide hydrolysis and combinations thereof as well as $\mathrm{O}$-glucuronidation of the $\mathrm{O}$-demethylated metabolite. The main metabolites both detected in vitro and in vivo were the $O$-demethylated metabolite and the hydrolysis product 4-ANPP. The findings of this study were consistent with unpublished data provided to the EMCDDA for risk assessment of methoxyacetylfentanyl (European Monitoring Centre for Drugs Drug Addiction [EMCDDA], 2018a).

\section{Ocfentanil}

This fentanyl analog has been developed and patented by Huang et al. (1986) and was evaluated for clinical application. Ocfentanil (N-(2-fluorophenyl)-2-methoxy- $N$-[1-(2-phenylethyl)-4-

piperidinyl]acetamide) is the ortho-fluorinated analog of methoxyacetylfentanyl and has also been subject to the studies of Bagley et al. (1991). They determined an $\mathrm{ED}_{50}$ value of $0.0077 \mathrm{mg} / \mathrm{kg}$ for ocfentanil using the mouse hot plate test for evaluation of analgesic effects. Compared to fentanyl $(0.018 \mathrm{mg} / \mathrm{kg})$ the potency can be estimated to be about 2.5 times higher than for fentanyl. At the same time, ocfentanil showed less respiratory depression in animal studies. Fletcher et al. (1991) investigated dose-dependent pharmacologic effects in humans but were not able to draw conclusions from the study regarding a benefit of ocfentanil over fentanyl.
Allibe et al. (2018) performed metabolism studies on ocfentanil using human liver microsomes in addition to metabolism profiling in post mortem samples of a fatal intoxication case. Ocfentanil was found in all biological samples except nasal swab and concentrations were similar in peripheral blood and cardiac blood (Allibe et al., 2018). This observation is in contrast to results in two previously reported fatalities which observed significant deviations of the cardiac/peripheral blood concentration ratio (Coopman et al., 2016; Dussy et al., 2016).

Four metabolites were detected in vitro by Allibe et al. (2018) formed by hydroxylation (at the phenylethyl moiety), $O$-demethylation and combination of both reactions as well as the conjugation product of the $O$-demethyl metabolite with glucuronic acid. The main metabolite in vitro and in vivo clearly was $O$-demethyl ocfentanil, presumably even exceeding quantities of the parent compound (when comparing peak areas). In contrast, commonly seen biotransformations such as $N$-dealkylation and amide hydrolysis have not been detected in this work, suggesting that these metabolic reactions only play a minor role in metabolism of ocfentanil.

\section{Ortho-Fluorofentanyl}

Ortho-fluorofentanyl ( $N$-(2-fluorophenyl)- $N$-[1-(2-phenylethyl) -4-piperidinyl]-propanamide) is a fluorinated fentanyl derivative. No data on receptor binding is available for this compound so far. However, the para-substituted analog was included in the studies performed by Higashikawa and Suzuki (2008a) and showed about $30 \%$ the potency of fentanyl determined by $\mathrm{ED}_{50}$ values. The $\mathrm{LD}_{50}$ values of $9.3 \mathrm{mg} / \mathrm{kg}$ for $p$-fluorofentanyl compared to $63 \mathrm{mg} / \mathrm{kg}$ for fentanyl indicate a higher toxicity of the fluorinated compound. The only study reporting metabolite identification of ortho-fluorofentanyl so far was a case report from Denmark by Andreasen et al. (2017). They detected the $N$-dealkylation product ortho-fluoro-norfentanyl in blood by HRMS techniques. Other potential metabolites like hydroxyortho-fluorofentanyl, hydroxy-ortho-fluoro-norfentanyl or the hydrolysis product ortho-fluoro-despropionylfentanyl were not detected in the authentic case sample. However, a urine sample was not part of the investigation, which could be the reason for the limited number of detected metabolites. The amide hydrolysis product ortho-fluoro-despropionylfentanyl has been reported to the EMCDDA as a fentanyl analog marketed independently, but further data on this compound is not available so far. A case report from Helland et al. (2017) focuses on the identification of ortho-fluorofentanyl and problems with the distinction of stereo-isomers. In this work the authors emphasize the necessity of integrating fluorinated analogs into general analytical screening procedures.

\section{Tetrahydrofuranylfentanyl}

The binding affinity of tetrahydrofuranylfentanyl (THFF, $N$-phenyl-N-[1-(2-phenylethyl)piperidin-4-yl]oxolane-2-carboxamide) was determined by the United States Drug Enforcement Administration (DEA) using $\mathrm{CHO}$ and rat cell preparations for opioid receptor expression. $K_{\mathrm{i}}$ values for THFF were $0.95 \pm 0.32 \mathrm{nM}$ ( $\mu$-OR vs. $\left[{ }^{3} \mathrm{H}\right]$-DAMGO), compared to $741 \pm 44 \mathrm{nM}$ (vs. $\left.\left[{ }^{3} \mathrm{H}\right]-\mathrm{U}-69593\right)$ and $1,730 \pm 260 \mathrm{nM}$ 
TABLE 1 | Summary of the reviewed fentanyl analogs and their metabolites and metabolic pathways.

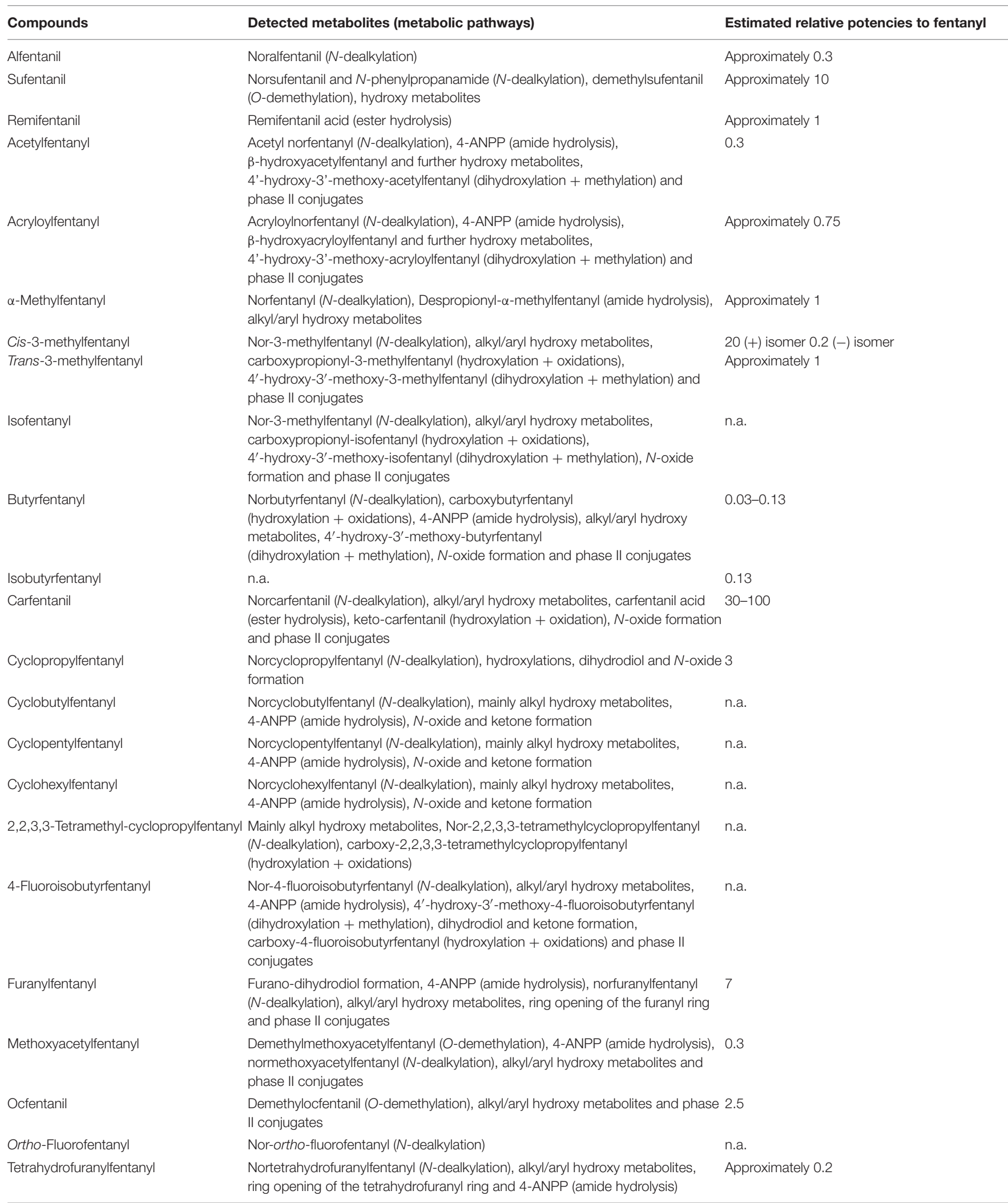

Estimated relative potencies compared to fentanyl (set to 1) are also given (n.a., no data available). 
(vs. $\left[{ }^{3} \mathrm{H}\right]$-DPDPE) for the $\delta$ - and $\kappa$-opioid receptors, respectively, showing high selectively for the $\mu$-opioid receptor. $\mathrm{EC}_{50}$ values were determined in vitro employing an $\left[{ }^{35} \mathrm{~S}\right] \mathrm{GTP} \gamma \mathrm{S}$ binding assay and resulted in $89 \pm 16 \mathrm{nM}$ for THFF at the $\mu$-opioid receptor. The authors report a lower potency compared to fentanyl for this compound (European Monitoring Centre for Drugs Drug Addiction [EMCDDA], 2018c).

Data provided to the EMCDDA for risk assessment of THFF propose $N$-dealkylation to be the predominant metabolic step for THFF in human liver microsomal preparations, as in the case of fentanyl. Hydroxylation of the piperidine ring and the phenylethyl side chain, $\mathrm{N}$-oxidation and amide hydrolysis to 4-ANPP were also observed (European Monitoring Centre for Drugs Drug Addiction [EMCDDA], 2018c).

Metabolic profiling of THFF was performed by Krotulski et al. (2018) to assist analytical identification of THFF in a fatality. Overall, seven metabolites were identified in vitro for THFF using pooled human liver microsomes. The hydroxylated metabolite species produced multiple, indistinguishable signals for hydroxylations at the tetrahydrofuranyl ring or the phenylethyl moiety. One of the major metabolites in vitro was nortetrahydrofuranylfentanyl formed by $N$-dealkylation, which proofed to be an applicable biomarker for THFF ingestion in biological samples. The hydroxylated species were also prominently detected in post mortem blood and urine samples. The hydrolysis product 4-ANPP was not unequivocally identified as a metabolite in this study (for analytical reasons), but may be considered as a possible minor metabolite since another hydroxylated metabolite (hydroxyl-4-ANPP) was also identified. Additionally, a biotransformation product presumably formed by oxidation of the tetrahydrofuranyl moiety and subsequent 'internal hydrolysis' under ring-opening was identified (Krotulski et al., 2018).

A short summary of the reviewed fentanyl analogs and their main metabolites (and metabolic pathways) described in the literature and estimated relative potencies (compared to fentanyl) are listed in Table $\mathbf{1 .}$

A number of further fentanyl analogs have been reported to the EMCDDA (mainly referring to seizures by police or customs

\section{REFERENCES}

Alburges, M. E., Hanson, G. R., Gibb, J. W., Sakashita, C. O., and Rollins, D. E. (1992). Fentanyl receptor assay II. Utilization of a radioreceptor assay for the analysis of fentanyl analogs in urine. J. Anal. Toxicol. 16, 36-41. doi: 10.1093/ jat/16.1.36

Allibe, N., Richeval, C., Phanithavong, M., Faure, A., Allorge, D., Paysant, F., et al. (2018). Fatality involving ocfentanil documented by identification of metabolites. Drug Test. Anal. 10, 995-1000. doi: 10.1002/dta. 2326

Andreasen, M. F., Hardlei, T. F., Rosendal, I., Thomsen, A. H., Johannsen, M., and Saedder, E. (2017). "A fatal poisoning involving 2-fluorofentanyl," in Proceedings of the 55th SOFT-TIAFT 2017 Annual Meeting, Boca Raton, FL.

Armenian, P., Vo, K. T., Barr-Walker, J., and Lynch, K. L. (2018). Fentanyl, fentanyl analogs and novel synthetic opioids: a comprehensive review. Neuropharmacology 134, 121-132. doi: 10.1016/j.neuropharm.2017. 10.016

Åstrand, A., Töreskog, A., Watanabe, S., Kronstrand, R., Gréen, H., and Vikingsson, S. (2018). Correlations between metabolism and authorities or intoxication cases) and were included into the literature search. However, no data on potency, receptor binding or metabolism was available yet. For the sake of completeness these compounds will be listed here in alphabetical order:

2-fluoroisobutyrfentanyl, 2-methyl-acetylfentanyl, 3-methylcrotonylfentanyl (senecionyl fentanyl), 3-fluorofentanyl, 3phenylpropanoylfentanyl, 4-chloroisobutyrfentanyl, 4-fluorobutyrfentanyl, 4-fluoro-cyclopropylbenzylfentanyl, 4-fluorofentanyl, 4-fluoroisobutyrfentanyl $N$-benzyl analog, 4-methoxybutyrfentanyl, $\alpha$-methylfentanyl butanamide analog (2-methyl -N-phenyl- $N$-[1-(1-phenyl-propan-2-yl)piperidine-4-yl]propanamide), acetyl benzylfentanyl, benzodioxolefentanyl, benzoylbenzylfentanyl, benzoylfentanyl, benzylfentanyl, crotonylfentanyl, furanylbenzylfentanyl, furanylethylfentanyl, furanylfentanyl-3carboxamide isomer, thiophenefentanyl and valerylfentanyl.

\section{AUTHOR CONTRIBUTIONS}

RS, SP, RP, AT, FB, VA, and MW searched for bibliographic material, drafted different chapter of the manuscript, and contributed substantially to manuscript intellectual content and revision.

\section{FUNDING}

This work was supported by the European Union's Programme - Drugs Policy Initiatives (grant agreement number: 806996JUSTSO; call JUST-2017-AG-DRUG) and by the Department for Antidrug Policies, Presidency of the Council of Ministers, Italy.

\section{ACKNOWLEDGMENTS}

The authors thank Mrs. Simonetta di Carlo, Mrs. Antonella Bacosi, Mrs. Laura Martucci, and Mr. Michele Sciotti. Oronzo Persano is acknowledged for technical assistance.

structural elements of the alicyclic fentanyl analogs cyclopropyl fentanyl, cyclobutyl fentanyl, cyclopentyl fentanyl, cyclohexyl fentanyl and 2,2,3,3tetramethylcyclopropyl fentanyl studied by human hepatocytes and LC-QTOF-MS. Arch. Toxicol. 93, 95-106. doi: 10.1007/s00204-018-2330-9

Bagley, J. R., Kudzma, L. V., Lalinde, N. L., Colapret, J. A., Huang, B.-S., Lin, B.S., et al. (1991). Evolution of the 4-anilidopiperidine class of opioid analgesics. Med. Res. Rev. 11, 403-436. doi: 10.1002/med.2610110404

Banks, H. D., and Ferguson, C. P. (1988). The Metabolites of Fentanyl and its Derivatives. Aberdeen, MD: Chemical Research Development \& Engeneering Center.

Bernard, S. A., and Bruera, E. (2000). Drug interactions in palliative care. J. Clin. Oncol. 18, 1780-1799. doi: 10.1200/JCO.2000.18.8.1780

Bespalov, A., Müller, R., Relo, A.-L., and Hudzik, T. (2016). Drug tolerance: a known unknown in translational neuroscience. Trends Pharmacol. Sci. 37, 364-378. doi: 10.1016/j.tips.2016.01.008

Bista, S. R., Lobb, M., Haywood, A., Hardy, J., Tapuni, A., and Norris, R. (2014). Development, validation and application of an HPLC-MS/MS method for the determination of fentanyl and nor-fentanyl in human plasma and saliva. J. Chromatogr. B 960, 27-33. doi: 10.1016/j.jchromb.2014.04.019 
Bi-Yi, C., Wen-Qiao, J., Jie, C., Xin-Jian, C., You-Cheng, Z., and Zhi-Qiang, C. (1999). Analgesic activity and selectivity of isothiocyanate derivatives of fentanyl analogs for opioid receptors. Life Sci. 65, 1589-1595. doi: 10.1016/ S0024-3205(99)00404-X

Brine, G. A., Stark, P. A., Liu, Y., Carroll, F. I., Singh, P., Xu, H., et al. (1995). Enantiomers of diastereomeric cis-N-[1-(2-Hydroxy-2-phenylethyl)-3-methyl4-piperidyl]-N-phenylpropanamides: synthesis, X-ray analysis, and biological activities. J. Med. Chem. 38, 1547-1557. doi: 10.1021/jm00009a015

Cascone, S., Lamberti, G., Piazza, O., Abbiati, R. A., and Manca, D. (2018). A physiologically-based model to predict individual pharmacokinetics and pharmacodynamics of remifentanil. Eur. J. Pharm. Sci. 111, 20-28. doi: 10.1016/ j.ejps.2017.09.028

Coopman, V., Cordonnier, J., De Leeuw, M., and Cirimele, V. (2016). Ocfentanil overdose fatality in the recreational drug scene. Forensic Sci. Int. 266(Suppl. C), 469-473. doi: 10.1016/j.forsciint.2016.07.005

Costa, E. M., Hoffman, B. B., and Loew, G. H. (1992). Opioid agonists binding and responses in SH-SY5Y cells. Life Sci. 50, 73-81. doi: 10.1016/0024-3205(92) 90199- Y

DePriest, A. Z., Puet, B. L., Holt, A. C., Roberts, A., and Cone, E. J. (2015). Metabolism and disposition of prescription opioids: a review. Forensic Sci. Rev. $27,115-145$

Donk, T., Ward, S., Langford, R., and Dahan, A. (2018). Pharmacokinetics and pharmacodynamics of sublingual sufentanil for postoperative pain management. Anaesthesia 73, 231-237. doi: 10.1111/anae. 14132

Drug Enforcement Administration-Veterans Affairs (DEA-VA) Interagency Agreement (2017). N-(1-Phenethylpiperidin-4-yl)- $N$ phenylcyclopropanecarboxamide, $\mathrm{HCl}$ Binding and Functional Activity at Delta, Kappa and Mu Opioid Receptors. In Vitro Receptor and Transporter Assays for Abuse Liability Testing for the DEA by the VA. Springfield, VA: Drug Enforcement Administration.

Drug Enforcement Administration-Veterans Affairs (DEA-VA) Interagency Agreement (2016). N-phenyl-N-[1-(2-phenylethyl)-4-piperidinyl]-2-furancarboxamide, mononhydrochloride Binding and Functional Activity at Delta, Kappa and $\mathrm{Mu}$ Opioid Receptors. In Vitro Receptor and Transporter Assays for Abuse Liability Testing for the DEA by the VA. Springfield, VA: Drug Enforcement Administration.

Dussy, F. E., Hangartner, S., Hamberg, C., Berchtold, C., Scherer, U., Schlotterbeck, G., et al. (2016). An acute ocfentanil fatality: a case report with postmortem concentrations. J. Anal. Toxicol. 40, 761-766. doi: 10.1093/jat/ bkw096

Essawi, M. Y. (1999). Fentanyl analogues with a modified propanamido group as potential affinity labels: synthesis and in vivo activity. Die Pharmazie 54, 307-308.

European Monitoring Centre for Drugs Drug Addiction [EMCDDA] (2017). Report on the Risk Assessment of N-phenyl-N-[1-(2-phenylethyl)piperidin-4$y l$-furan-2-Carboxamide (furanylfentanyl) in the Framework of the Council Decision on New Psychoactive Substances, Risk Assessments. Luxembourg: Publications Office of the European Union.

European Monitoring Centre for Drugs Drug Addiction [EMCDDA] (2018a). EMCDDA-Europol Joint Report on a New Psychoactive Substance: 2-Methoxy-N-Phenyl-N-[1-(2-phenylethyl) Piperidin-4-yl]Acetamide (Methoxyacetylfentanyl), Joint Reports. Luxembourg: Publications Office of the European Union.

European Monitoring Centre for Drugs Drug Addiction [EMCDDA] (2018b). Report on the Risk Assessment of N-phenyl-N-[1-(2-phenylethyl)piperidin4-yl]Cyclopropanecarboxamide (cyclopropylfentanyl) in the Framework of the Council Decision on New Psychoactive Substances, Risk Assessments. Luxembourg: Publications Office of the European Union.

European Monitoring Centre for Drugs Drug Addiction [EMCDDA] (2018c). Report on the Risk Assessment of N-phenyl-N-[1-(2-phenylethyl)piperidin-4$y l$ loxolane-2-carboxamide (tetrahydrofuranylfentanyl; THF-F) in the framework of the Council Decision on new Psychoactive substances, Risk Assessments. Luxembourg: Publications Office of the European Union.

Feasel, M. G., Wohlfarth, A., Nilles, J. M., Pang, S., Kristovich, R. L., and Huestis, M. A. (2016). Metabolism of carfentanil, an ultra-potent opioid, in human liver microsomes and human hepatocytes by high-resolution mass spectrometry. AAPS J. 18, 1489-1499. doi: 10.1208/s12248-016-9963-5
Feierman, D. E., and Lasker, J. M. (1996). Metabolism of fentanyl, a synthetic opioid analgesic, by human liver microsomes. Role of CYP3A4. Drug Metab. Dispos. 24, 932-939.

Fletcher, J. E., Sebel, P. S., Murphy, M. R., Mick, S. A., and Fein, S. (1991). Comparison of ocfentanil and fentanyl as supplements to general anesthesia. Anesth. Analg. 73, 622-626. doi: 10.1213/00000539-199111000-00019

Fragen, R. J., Booij, L. H. D. J., Braak, G. J. J., Vree, T. B., Heykants, J., and Crul, J. F. (1983). Pharmacokinetics of the infusion of alfentanil in man. Br. J. Anaesth. 55, 1077-1081. doi: 10.1093/bja/55.11.1077

France, C. P., Gerak, L. R., Flynn, D., Winger, G. D., Medzihradsky, F., Bagley, J. R., et al. (1995). Behavioral effects and receptor binding affinities of fentanyl derivatives in rhesus monkeys. J. Pharmacol. Exp. Ther. 274, 17-28.

Gillespie, T. J., Gandolfi, A. J., Davis, T. P., and Morano, R. A. (1982). Identification and quantification of alpha-methylfentanyl in post mortem specimens. J. Anal. Toxicol. 6, 139-142. doi: 10.1093/jat/6.3.139

Goggin, M. M., Nguyen, A., and Janis, G. C. (2017). Identification of unique metabolites of the designer opioid furanyl fentanyl. J. Anal. Toxicol. 41, 367-375. doi: 10.1093/jat/bkx022

Goromaru, P. D. T., Matsuura, P. D. H., Yoshimura, M. D. N., Miyawaki, M. D. T., Sameshima, B. A. T., Miyao, B. A. J., et al. (1984). Identification and quantitative determination of fentanyl metabolites in patients by gas chromatographymass spectrometry anesthesiology. Anesthesiology 61, 73-77. doi: 10.1097/ 00000542-198407000-00013

Gudin, J. (2012). Opioid therapies and cytochrome P450 interactions. J. Pain Symptom Manage 44, S4-S14. doi: 10.1016/j.jpainsymman.2012.08.013

Guitton, J., Buronfosse, T., Désage, M., Lepape, A., Brazier, J.-L., and Beaune, P. (1997). Possible involvement of multiple cytochrome P450S in fentanyl and sufentanil metabolism as opposed to alfentanil. Biochem. Pharmacol. 53, 1613-1619. doi: 10.1016/S0006-2952(96)00893-3

Hammargren, W. R., and Henderson, G. L. (1988). Analyzing normetabolites of the fentanyls by gas chromatography/electron capture detection. J. Anal. Toxicol. 12, 183-191. doi: $10.1093 /$ jat $/ 12.4 .183$

Helland, A., Brede, W. R., Michelsen, L. S., Gundersen, P. O. M., Aarset, H., Skjølås, J. E., et al. (2017). Two hospitalizations and one death after exposure to ortho-fluorofentanyl. J. Anal. Toxicol. 41, 708-709. doi: 10.1093/jat/ bkx050

Henriksen, G., Platzer, S., Marton, J., Hauser, A., Berthele, A., Schwaiger, M., et al. (2005). Syntheses, biological evaluation, and molecular modeling of 18f-labeled 4 -anilidopiperidines as $\mu$-opioid receptor imaging agents. J. Med. Chem. 48, 7720-7732. doi: $10.1021 / \mathrm{jm} 0507274$

Higashikawa, Y., and Suzuki, S. (2008a). Studies on 1-(2-Phenethyl)-4-(Npropionylanilino)piperidine (fentanyl) and its related compounds: novel metabolites in rat urine following injection of alpha-methylfentanyl, one of the most abused typical designer drugs. J. Health Sci. 54, 629-637. doi: 10.1248/jhs. 54.629

Higashikawa, Y., and Suzuki, S. (2008b). Studies on 1-(2-phenethyl)-4(N-propionylanilino)piperidine (fentanyl) and its related compounds. VI. Structure-analgesic activity relationship for fentanyl, methyl-substituted fentanyls and other analogues. Forensic Toxicol. 26, 1-5. doi: 10.1007/s11419007-0039-1

Huang, B.-S., Terrell, R. C., Deutsche, K. H., Kudzma, L. V., and Lalinde, N. L. (1986). N-aryl-N-(4-piperidinyl)amides and pharmaceutical compositions and method employing such compounds. U.S. Patent No 4584303A. New Providence, NJ: Anaquest Inc.

Ingoglia, N. A., and Dole, V. P. (1970). Localization of $\mathrm{d}$ and 1 methadone after interventricular injection into rat brains. J. Pharmacol. Exp. Ther. 175, 84-87.

Janssen, P. A. (1965). 1-aralkyl-4-(n-aryl-carbonyl amino)-piperidines and related compounds. U.S. Patent No 5100903A. Madison, WI: Datex Ohmeda Inc.

Janssen, P. A. (1979). N-(4-piperidinyl)-N-phenylamides. U.S. Patent No 4179569A. Beerse: Janssen Pharmaceutica NV.

Jewett, D. M., and Kilbourn, M. R. (2004). In vivo evaluation of new carfentanilbased radioligands for the mu opiate receptor. Nuclear Med. Biol. 31, 321-325. doi: 10.1016/j.nucmedbio.2003.10.009

Jiang, H. L., Huang, X. Q., Rong, S. B., Luo, X. M., Chen, J. Z., Tang, Y., et al. (2000). Theoretical studies on opioid receptors and ligands. I. Molecular modeling and QSAR studies on the interaction mechanism of fentanyl analogs binding to $\mu$-opioid receptor. Int. J. Quant. Chem. 78, 285-293. doi: 10.1002/(SICI)1097$461 \mathrm{X}(2000) 78: 4<285::$ AID-QUA11>3.0.CO;2-I 
Kanamori, T., Togawa Iwata, Y., Segawa, H., Yamamuro, T., Kuwayama, K., Tsujikawa, K., et al. (2018a). Metabolism of fentanyl and acetylfentanyl in human-induced pluripotent stem cell-derived hepatocytes. Biol. Pharm. Bull. 41, 106-114. doi: 10.1248/bpb.b17-00709

Kanamori, T., Togawa-Iwata, Y., Segawa, H., Yamamuro, T., Kuwayama, K., Tsujikawa, K., et al. (2018b). Use of hepatocytes isolated from a liver-humanized mouse for studies on the metabolism of drugs: application to the metabolism of fentanyl and acetylfentanyl. Forensic Toxicol. 36, 467-475. doi: 10.1007/s11419018-0425-x

Kokubun, H., Ebinuma, K., Matoba, M., Takayanagi, R., Yamada, Y., and Yago, K. (2012). Population pharmacokinetics of transdermal fentanyl in patients with cancer-related pain. J. Pain Palliat. Care Pharmacother. 26, 98-104. doi: 10.3109/15360288.2012.679725

Koyyalagunta, D. (2007). “Opioid analgesics," in Pain Management, ed. S.D. Waldmann. Saunders: Philadelphia, PA, 939-964. doi: 10.1016/B978-0-72160334-6.50117-5

Krotulski, A. J., Papsun, D. M., Friscia, M., Swartz, J. L., Holsey, B. D., and Logan, B. K. (2018). Fatality following ingestion of tetrahydrofuranylfentanyl, U-49900 and methoxy-phencyclidine. J. Anal. Toxicol. 42, e27-e32. doi: 10.1093/jat/ bkx092

Kuip, E. J. M., Zandvliet, M. L., Koolen, S. L. W., Mathijssen, R. H. J., and Rijt, C. C. D. (2017). A review of factors explaining variability in fentanyl pharmacokinetics; focus on implications for cancer patients. Br. J. Clin. Pharmacol. 83, 294-313. doi: 10.1111/bcp.13129

Kukanich, B., and Papich, M. G. (2009). "Opioid analgesic drugs," in Veterinary Pharmacology and Therapeutics, 9th Edn, eds J. E. Riviere, M. G. Papich and H. R. Adams. (Hoboken, NJ: Wiley-Blackwell), 301-337.

Labroo, R. B., Paine, M. F., Thummel, K. E., and Kharasch, E. D. (1997). Fentanyl metabolism by human hepatic and intestinal cytochrome P450 3A4: implications for interindividual variability in disposition, efficacy, and drug interactions. Drug Metab. Dispos. 25, 1072-1080.

Lavrijsen, K., Van Houdt, J., Van Dyck, D., Hendrickx, J., Lauwers, W., Hurkmans, R., et al. (1990). Biotransformation of sufentanil in liver microsomes of rats, dogs, and humans. Drug Metab. Dispos. 18, 704-710.

Maguire, P., Tsai, N., Kamal, J., Cometta-Morini, C., Upton, C., and Loew, G. (1992). Pharmacological profiles of fentanyl analogs at $\mu, \delta$ and $\kappa$ opiate receptors. Eur. J. Pharmacol. 213, 219-225. doi: 10.1016/0014-2999(92) 90685-W

Maher, S., Elliott, S. P., and George, S. (2018). The analytical challenges of cyclopropylfentanyl and crotonylfentanyl: an approach for toxicological analysis. Drug Test. Anal. 10, 1483-1487. doi: 10.1002/dta.2417

Mahlke, N. S., Ziesenitz, V., Mikus, G., and Skopp, G. (2014). Quantitative lowvolume assay for simultaneous determination of fentanyl, norfentanyl, and minor metabolites in human plasma and urine by liquid chromatographytandem mass spectrometry (LC-MS/MS). Int. J. Legal Med. 128, 771-778. doi: 10.1007/s00414-014-1040-y

Marchei, E., Pacifici, R., Mannocchi, G., Marinelli, E., Busardò, F. P., and Pichini, S. (2018). New synthetic opioids in biological and non-biological matrices: A review of current analytical methods. Trends Analyt. Chem. 102, 1-15. doi: 10.1016/j.trac.2018.01.007

Mardal, M., Johansen, S. S., Davidsen, A. B., Telving, R., Jornil, J. R., Dalsgaard, P. W., et al. (2018). Postmortem analysis of three methoxyacetylfentanylrelated deaths in Denmark and in vitro metabolite profiling in pooled human hepatocytes. Forensic Sci. Int. 290, 310-317. doi: 10.1016/j.forsciint.2018.07.020

Martin, W. R. (1967). Opioid antagonists. Pharmacol. Rev. 19, 463-521.

Martucci, H. F. H., Ingle, E. A., Hunter, M. D., and Rodda, L. N. (2018). Distribution of furanyl fentanyl and 4-ANPP in an accidental acute death: a case report. Forensic Sci. Int. 283, e13-e17. doi: 10.1016/j.forsciint.2017.12.005

Maryanoff, B. E., Simon, E. J., Gioannini, T., and Gorissen, H. (1982). Potential affinity labels for the opiate receptor based on fentanyl and related compounds. J. Med. Chem. 25, 913-919. doi: 10.1021/jm00350a006

Melent'ev, A. B., Kataev, S. S., and Dvorskaya, O. N. (2015). Identification and analytical properties of acetyl fentanyl metabolites. J. Anal. Chem. 70, 240-248. doi: 10.1134/S1061934815020124

Mercadante, S. (2015). Opioid metabolism and clinical aspects. Eur. J. Pharmacol. 769, 71-78. doi: 10.1016/j.ejphar.2015.10.049

Meyer, M. R., Dinger, J., Schwaninger, A. E., Wissenbach, D. K., Zapp, J., Fritschi, G., et al. (2012). Qualitative studies on the metabolism and the toxicological detection of the fentanyl-derived designer drugs 3-methylfentanyl and isofentanyl in rats using liquid chromatography-linear ion trap-mass spectrometry (LC-MSn). Anal. Bioanal. Chem. 402, 1249-1255. doi: 10.1007/ s00216-011-5528-8

Mohr, A. L. A., Friscia, M., Papsun, D., Kacinko, S. L., Buzby, D., and Logan, B. K. (2016). Analysis of novel synthetic opioids U-47700, U-50488 and furanyl fentanyl by LC-MS/MS in postmortem casework. J. Anal. Toxicol. 40, 709-717. doi: 10.1093/jat/bkw086

National Institute on Drug Abuse [NIDA] (2016). Drug Facts Fentanyl. National Institutes of Health; U.S. Department of Health and Human Services. Available at: https://www.drugabuse.gov/publications/drugfacts/fentanyl

Palaty, J., Konforte, D., Karakosta, T., Wong, E., and Stefan, C. (2018). Rapid identification of cyclopropyl fentanyl/crotonyl fentanyl in clinical urine specimens: a case study of clinical laboratory collaboration in Canada. Clin. Biochem. 53, 164-167. doi: 10.1016/j.clinbiochem.2018.01.013

Pan, L., Xu, J., Yu, R., Xu, M. M., Pan, Y. X., and Pasternak, G. W. (2005). Identification and characterization of six new alternatively spliced variants of the human $\mu$ opioid receptor gene, Oprm. Neuroscience 133, 209-220. doi: 10.1016/j.neuroscience.2004.12.033

Panzer, O., Moitra, V., and Sladen, R. N. (2009). Pharmacology of sedativeanalgesic agents: dexmedetomidine, remifentanil, ketamine, volatile anesthetics, and the role of peripheral $\mathrm{Mu}$ antagonists. Crit. Care Clin. 25, 451-469. doi: 10.1016/j.ccc.2009.04.004

Patton, A. L., Seely, K. A., Pulla, S., Rusch, N. J., Moran, C. L., Fantegrossi, W. E., et al. (2014). Quantitative measurement of acetyl fentanyl and acetyl norfentanyl in human urine by LC-MS/MS. Anal. Chem. 86, 1760-1766. doi: $10.1021 /$ ac4036197

Pert, C. B., and Snyder, S. H. (1973). Opiate receptor: demonstration in nervous tissue. Science 179, 1011-1014. doi: 10.1126/science.179.4077.1011

Pichini, S., Pacifici, R., Marinelli, E., and Busardò, F. P. (2017). European Drug Users at Risk from Illicit Fentanyls Mix. Front. Pharmacol. 8:785. doi: 10.3389/ fphar.2017.00785

Pichini, S., Solimini, R., Berretta, P., Pacifici, R., and Busardò, F. P. (2018). Acute intoxications and fatalities from illicit fentanyl and analogues: an update. Ther. Drug Monit. 40, 38-51. doi: 10.1097/FTD.0000000000000465

Poonyachoti, S., Portoghese, P. S., and Brown, D. R. (2001). Pharmacological evidence for a 7-benzylidenenaltrexone-preferring opioid receptor mediating the inhibitory actions of Peptidic $\delta$ - and $\mu$-Opioid agonists on neurogenic ion transport in porcine ileal mucosa. J. Pharmacol. Exp. Ther. 297, 672-679.

Portoghese, P. S., and Lunzer, M. M. (2003). Identity of the putative $\delta 1$-opioid receptor as a $\delta-\kappa$ heteromer in the mouse spinal cord. Eur. J. Pharmacol. 467, 233-234. doi: 10.1016/S0014-2999(03)01599-1

Riches, J. R., Read, R. W., Black, R. M., Cooper, N. J., and Timperley, C. M. (2012). Analysis of clothing and urine from moscow theatre siege casualties reveals carfentanil and remifentanil use. J. Anal. Toxicol. 36, 647-656. doi: 10.1093/jat/bks078

Richeval, C., Gicquel, T., Hugbart, C., Le Dare, B., Allorge, D., Morel, I., et al. (2017). In vitro characterization of NPS metabolites produced by human liver microsomes and the HepaRG cell line using liquid chromatographyhigh resolution mass spectrometry (LC-HRMS) analysis: application to furanyl fentanyl. Curr. Pharm. Biotechnol. 18, 806-814. doi: $10.2174 / 1389201018666171122124401$

Rosow, C. E. (1999). An overview of remifentanil. Anesth. Analg. 89, S1-S3. doi: 10.1097/00000539-199910001-00001

Rothberg, R. L., and Stith, K. (2018). Fentanyl: a whole new world? J. Law Med. Ethics 46, 314-324. doi: 10.1177/1073110518782937

Rothman, R. B., France, C. P., Bykov, V., De Costa, B. R., Jacobson, A. E., Woods, J. H., et al. (1989). Pharmacological activities of optically pure enantiomers of the $\kappa$ opioid agonist, U50,488, and its cis diastereomer: evidence for three $\kappa$ receptor subtypes. Eur. J. Pharmacol. 167, 345-353. doi: 10.1016/0014-2999(89) 90443-3

Sato, S., Suzuki, S., Lee, X.-P., and Sato, K. (2010). Studies on 1-(2-phenethyl)4-(N-propionylanilino)piperidine (fentanyl) and related compounds: VII. Quantification of $\alpha$-methylfentanyl metabolites excreted in rat urine. Forensic Sci. Int. 195, 68-72. doi: 10.1016/j.forsciint.2009.11.014

Schneider, E., and Brune, K. (1986). Opioid activity and distribution of fentanyl metabolites. Naunyn. Schmiedebergs Arch. Pharmacol. 334, 267-274. doi: 10.1007/BF00508781 
Simon, E. J., Hiller, J. M., and Edelman, I. (1973). Stereospecific binding of the potent narcotic analgesic $\left[{ }^{3} \mathrm{H}\right]$ etorphine to rat-brain homogenate. Proc. Natl. Acad. Sci. U.S.A. 70, 1947-1949. doi: 10.1073/pnas.70.7.1947

Skulska, A., Kała, M., and Parczewski, A. (2004). Fentanyl and its analogues in the forensic laboratory. Medical and analytical problems. Probl. Forensic. Sci. 59, $127-142$.

Solassol, I., Bressolle, F., Caumette, L., Garcia, F., Poujol, S., Culine, S., et al. (2005). Inter- and intraindividual variabilities in pharmacokinetics of fentanyl after repeated 72-hour transdermal applications in cancer pain patients. Ther. Drug Monit. 27, 491-498. doi: 10.1097/01.ftd.0000160717.50704.42

Staeheli, S. N., Baumgartner, M. R., Gauthier, S., Gascho, D., Jarmer, J., Kraemer, T., et al. (2016). Time-dependent postmortem redistribution of butyrfentanyl and its metabolites in blood and alternative matrices in a case of butyrfentanyl intoxication. Forensic Sci. Int. 266, 170-177. doi: 10.1016/j.forsciint.2016.05.034

Steuer, A. E., Williner, E., Staeheli, S. N., and Kraemer, T. (2017). Studies on the metabolism of the fentanyl-derived designer drug butyrfentanyl in human in vitro liver preparations and authentic human samples using liquid chromatography-high resolution mass spectrometry (LC-HRMS). Drug Test. Anal. 9, 1085-1092. doi: 10.1002/dta.2111

Streisand, J. B., Varvel, J. R., Stanski, D. R., Le Maire, L., Ashburn, M. A., Hague, B. I., et al. (1991). Absorption and bioavailability of oral transmucosal fentanyl citrate. Anesthesiology 75, 223-229. doi: 10.1097/00000542-199108000-00009

Subramanian, G., Paterlini, M. G., Portoghese, P. S., and Ferguson, D. M. (2000). Molecular docking reveals a novel binding site model for fentanyl at the $\mu$-Opioid receptor. J. Med. Chem. 43, 381-391. doi: 10.1021/jm9903702

Tateishi, T., Krivoruk, Y., Ueng, Y.-F., Wood, A. J. J., Guengerich, F. P., and Wood, M. (1996). Identification of human liver cytochrome P-450 3A4 as the enzyme responsible for fentanyl and sufentanil N-dealkylation. Anesth. Analg. $82,167-172$.

Terenius, L. (1973). Characteristics of the "receptor" for narcotic analgesics in synaptic plasma membrane fraction from rat Brain. Acta Pharmacol. Toxicol. 33, 377-384. doi: 10.1111/j.1600-0773.1973.tb01539.x

Thompson, R. G., Menking, D., and Valdes, J. J. (1987). Opiate Receptor Binding Properties of Carfentanil. Baltimore, MD: Chemical Research, Development \& Engineering Center. doi: 10.21236/ADA187637

Ujváry, I., Jorge, R., Christie, R., Le Ruez, T., Danielsson, H. V., Kronstrand, R., et al. (2017). Acryloylfentanyl, a recently emerged new psychoactive substance: a comprehensive review. Forensic Toxicol. 35, 232-243. doi: 10.1007/s11419017-0367-8

United Nations Office on Drugs and Crime [UNODC] (2017). Recommended Methods for the Identification and Analysis of Fentanyl and its Analogues in Biological Specimen. Vienna: UNODC

US Drug Enforcement Administration [US DEA] (2015) National Drug Threat Assessment. Report DEA-DCT-DIR-008-16; October 2015. Available at: https: //www.dea.gov/sites/default/files/2018-07/2015\%20NDTA\%20Report.pdf

Valaer, A. K., Huber, T., Andurkar, S. V., Clark, C. R., and DeRuiter, J. (1997). Development of a gas chromatographic-mass spectrometric drug screening method for the n-dealkylated metabolites of fentanyl, Sufentanil, and Alfentanil. J. Chromatogr. Sci. 35, 461-466. doi: 10.1093/chromsci/35.10.461

Van Bever, W. F., Niemegeers, C. J., Schellekens, K. H., and Janssen, P. A. (1976). N-4-Substituted 1-(2-arylethyl)-4-piperidinyl-N-phenylpropanamides, a novel series of extremely potent analgesics with unusually high safety margin. Arzneimittelforschung 26, 1548-1551.
Van Bever, W. F. M., Niemegeers, C. J. E., and Janssen, P. A. J. (1974). Synthetic analgesics. Synthesis and pharmacology of the diastereoisomers of N-[3-methyl-1-(2-phenylethyl)-4-piperidyl]-N-phenylpropanamide and $\mathrm{N}$-[3-methyl-1-(1-methyl-2-phenylethyl)-4-piperidyl]-N-phenylpropanamide. J. Med. Chem. 17, 1047-1051. doi: 10.1021/jm00256a003

Van Daele, P. G., De Bruyn, M. F., Boey, J. M., Sanczuk, S., Agten, J. T., and Janssen, P. A. (1976). Synthetic analgesics: N-(1-[2-arylethyl]-4-substituted 4-piperidinyl) N-arylalkanamides. Arzneimittelforschung 26, 1521-1531.

Van Praag, D., and Simon, E. J. (1966). Studies on the intracellular distribution and tissue binding of dihydromorphine-7,8-H3 in the rat. Proc. Soc. Exp. Biol. Med. 122, 6-11. doi: 10.3181/00379727-122-31036

Van Wijngaarden, I., and Soudijn, W. (1968). The metabolism and excretion of the analgesic fentanyl ( $\mathrm{R} 4263$ ) by wistar rats. Life Sci. 7, 1239-1244. doi: 10.1016/0024-3205(68)90236-1

Vardanyan, R. S., and Hruby, V. J. (2014). Fentanyl-related compounds and derivatives: current status and future prospects for pharmaceutical applications. Fut. Med. Chem. 6, 385-412. doi: 10.4155/fmc.13.215

Villemagne, V. L., James Frost, J., Dannals, R. F., Lever, J. R., Tanada, S., Natarajan, T. K., et al. (1994). Comparison of [11C]diprenorphine and [11C]carfentanil in vivo binding to opiate receptors in man using a dual detector system. Eur. J. Pharmacol. 257, 195-197. doi: 10.1016/0014-2999(94)90712-9

Volpe, D. A., Tobin, G. A. M., Mellon, R. D., Katki, A. G., Parker, R. J., Colatsky, T., et al. (2011). Uniform assessment and ranking of opioid Mu receptor binding constants for selected opioid drugs. Regul. Toxicol. Pharmacol. 59, 385-390. doi: 10.1016/j.yrtph.2010.12.007

Vuckovic, S., Prostran, M., Ivanovic, M., Dosen-Micovic, L., Todorovic, Z., Nesic, Z., et al. (2009). Fentanyl analogs: structure-activity-relationship study. Curr. Med. Chem. 16, 2468-2474. doi: 10.2174/092986709788682074

Wang, Z.-X., Zhu, Y.-C., Jin, W.-Q., Chen, X.-J., Chen, J., Ji, R.-Y., et al. (1995). Stereoisomers of N-[1-(2-Hydroxy-2-phenylethyl)-3-methyl4-piperidyl]- N-phenylpropanamide: synthesis, stereochemistry, analgesic activity, and opioid receptor binding characteristics. J. Med. Chem. 38, 3652-3659. doi: 10.1021/jm00018a026

Watanabe, S., Vikingsson, S., Roman, M., Green, H., Kronstrand, R., and Wohlfarth, A. (2017). In vitro and in vivo metabolite identification studies for the new synthetic opioids acetylfentanyl, acrylfentanyl, furanylfentanyl, and 4-fluoro-isobutyrylfentanyl. AAPS J. 19, 1102-1122. doi: 10.1208/s12248-0170070-z

Wu, F., Slawson, M. H., and Johnson-Davis, K. L. (2017). Metabolic patterns of fentanyl, meperidine, methylphenidate, tapentadol and tramadol observed in urine, serum or plasma. J. Anal. Toxicol. 41, 289-299. doi: 10.1093/jat/bkx003

Conflict of Interest Statement: The authors declare that the research was conducted in the absence of any commercial or financial relationships that could be construed as a potential conflict of interest.

Copyright (c) 2019 Wilde, Pichini, Pacifici, Tagliabracci, Busardò, Auwärter and Solimini. This is an open-access article distributed under the terms of the Creative Commons Attribution License (CC BY). The use, distribution or reproduction in other forums is permitted, provided the original author(s) and the copyright owner(s) are credited and that the original publication in this journal is cited, in accordance with accepted academic practice. No use, distribution or reproduction is permitted which does not comply with these terms. 